Article

\title{
Provision of Supplementary Load Frequency Control via Aggregation of Air Conditioning Loads
}

\author{
Lei Zhou, Yang Li *, Beibei Wang, Zhe Wang and Xiaoqing $\mathrm{Hu}$ \\ Received: 9 October 2015; Accepted: 7 December 2015; Published: 14 December 2015 \\ Academic Editor: Josep M. Guerrero \\ Department of Electrical Engineering, Southeast University, No. 2 Sipailou, Nanjing 210096, Jiangsu, China; \\ zhouleiseu@gmail.com (L.Z.); wangbeibei@seu.edu.cn (B.W.); bigtimewang3168@sina.com (Z.W.); \\ happysnow2004@126.com (X.H.) \\ * Correspondence: li_yang@seu.edu.cn; Tel.: +86-139-5160-6563; Fax: +86-25-8379-3371
}

\begin{abstract}
The integration of large-scale renewable energy poses great challenges for the operation of power system because of its increased frequency fluctuations. More load frequency control (LFC) resources are demanded in order to maintain a stable system with more renewable energy injected. Unlike the costly LFC resources on generation side, the thermostatically controlled loads (TCLs) on the demand side become an attractive solution on account of its substantial quantities and heat-storage capacity. It generally contains air conditioners (ACs), water heaters and fridges. In this paper, the supplementary LFC is extracted by the modeling and controlling of aggregated ACs. We first present a control framework integrating the supplementary LFC with the traditional LFC. Then, a change-time-priority-list method is proposed to control power output taking into account customers' satisfaction. Simulations on a single-area power system with wind power integration demonstrate the effectiveness of the proposed method. The impact of ambient temperature changes and customer preferences on room temperature is also involved in the discussion. Results show that the supplementary LFC provided by ACs could closely track the LFC signals and effectively reduce the frequency deviation.
\end{abstract}

Keywords: demand response; thermostatically controlled loads (TCLs); air conditioner (AC); load frequency control (LFC); change-time-priority-list method; renewable energy integration

\section{Introduction}

With fossil energy running out, the power system has installed a large amount of generation from renewable energy sources such as wind power generation and photovoltaic generation [1,2]. The intermittency of renewable generation has posed significant challenges for the operation and stability of the power system. One prominent problem is that the increased frequency fluctuation demands highly on load frequency control (LFC) resources to balance supply and demand at all times [3,4].

Frequency in the power system is usually controlled by adjusting the generation in response to changes in the load $[5,6]$. However, this method would make the regulating generators diverge from the optimal operation point and result in low efficiencies and short service life. Sometimes, even new regulating generators are needed to maintain a stable system.

Demand response (DR) [7] provides a more effective and lower-priced solution than adding new regulating generators on the supply side. DR changes load from passive to active, making it possible to exert impact on power system operation. Thermostatically controlled load (TCLs) [8,9], a controllable active load, encompasses devices such as air conditioners (ACs), fridges, space and water heaters, which occupy most of the residential energy demand [10]. ACs are selected as ideal controllable loads because of its capability of energy transformation and storage [11]. Customer 
satisfaction is also taken into consideration through appropriate control of AC temperature and on/off [12]. For instance, frequency decline could be stopped through adjusting setting temperature and orderly turning off ACs. Similarly, frequency increase also could be stopped through adjusting setting temperature and orderly turning on ACs.

Many researchers adopt the equivalent thermal parameters (ETP) model [13] to depict the relationship between indoor, ambient temperature and AC power consumption. This simplified model is suited for simulating residential and small commercial buildings. Load of a single AC resembles the square signal; while a load of aggregated ACs becomes a continuous curve. Therefore, most papers focus on aggregated load control. Researches on the thermal storage potential of TCLs were recognized as early as the 1980s [14-16]. Malhame and Chong [16] firstly proposed a statistical approach to use a system of coupled Fokker-Planck equations to describe a cluster of TCLs. Based on the above study, Reference [9] presented a new DR project to provide load following service by controlling aggregated TCLs under Fokker-Planck diffusion models. As a follow-up work of the method, a centralized DR control algorithm considering customer satisfaction was proposed in $[17,18]$. Reference [19] presented a non-uniform bin model-an extension of the uniform bin models in [20-22], with the only difference being the length of each bin. References [23-25] focused on identifying the model parameters from a real population of devices and applying to DR project. Reference [26] designed a state-queuing model (SQ model) to depict AC operation, by which aggregated AC load performance under different power prices was analyzed. A temperature-priority-list model and dispatch algorithm were presented in $[27,28]$ to optimize the control sequence of TCLs and reduce the communication and computation burdens between the centralized controller and individual devices. Reference [29] constructed a control algorithm coordinating TCLs and battery to improve power quality by smoothing power oscillations caused by the renewable generation resources in the microgrid. The Parameter selection of the temperature-priority-list model was conducted in [30].

This paper focuses on integrating aggregated TCLs into the power system. We present a change-time-priority-list method for dispatching a collection of ACs for supplementary load frequency control and smoothing the frequency fluctuations caused by wind power integration. A control framework is implemented to combine the Supplementary LFC with the traditional LFC. Simulations on a single-area power system with wind power integration demonstrate the effectiveness and robustness of the proposed method. This paper also considers the impact of outdoor temperature changes and indoor temperature preferences. Results show that the Supplementary LFC provided by ACs could closely track the LFC signals and effectively reduce the frequency deviation as well as maintain customer's comfort and load diversity.

The remainder of this paper is organized as follows. The control framework of Supplementary LFC and the AC thermal dynamic model is presented in Section 2; the change-time-priority-list method and the study system are introduced in Section 3; simulations and discussions on performances of the proposed method are demonstrated in Section 4; the final conclusion is summarized in Section 5.

\section{Modeling Methodologies}

\subsection{Control Framework of Supplementary Load Frequency Control}

Figure 1 shows the bi-level control framework of combining the supplementary LFC with the traditional LFC and a two-way communication network is assumed. On the macro level, the load dispatching center not only communicates with load aggregators to obtain aggregated AC power limits but also detects frequency or tie-line power fluctuations. LFC signals are distributed to thermal power plant and load aggregators according to information mentioned above. On the micro level, the signed contract entitled aggregators to partially control these ACs. The key point of the micro level is the Change-time-priority-list method, which will be introduced at length in the next chapter. 
For one thing, this method could estimate the aggregated AC power limits from collected data like on/off state, ambient temperature changes and customer setting temperature preferences, and the power limits will be sent to the load dispatching center by each aggregator. For another, this method provides the control schedule according to the received Supplementary LFC signal.

Note that this paper mainly emphasizes how to control the aggregated ACs for the supplementary LFC; therefore, the impact of customer incentive and communication cost are not discussed in this paper.

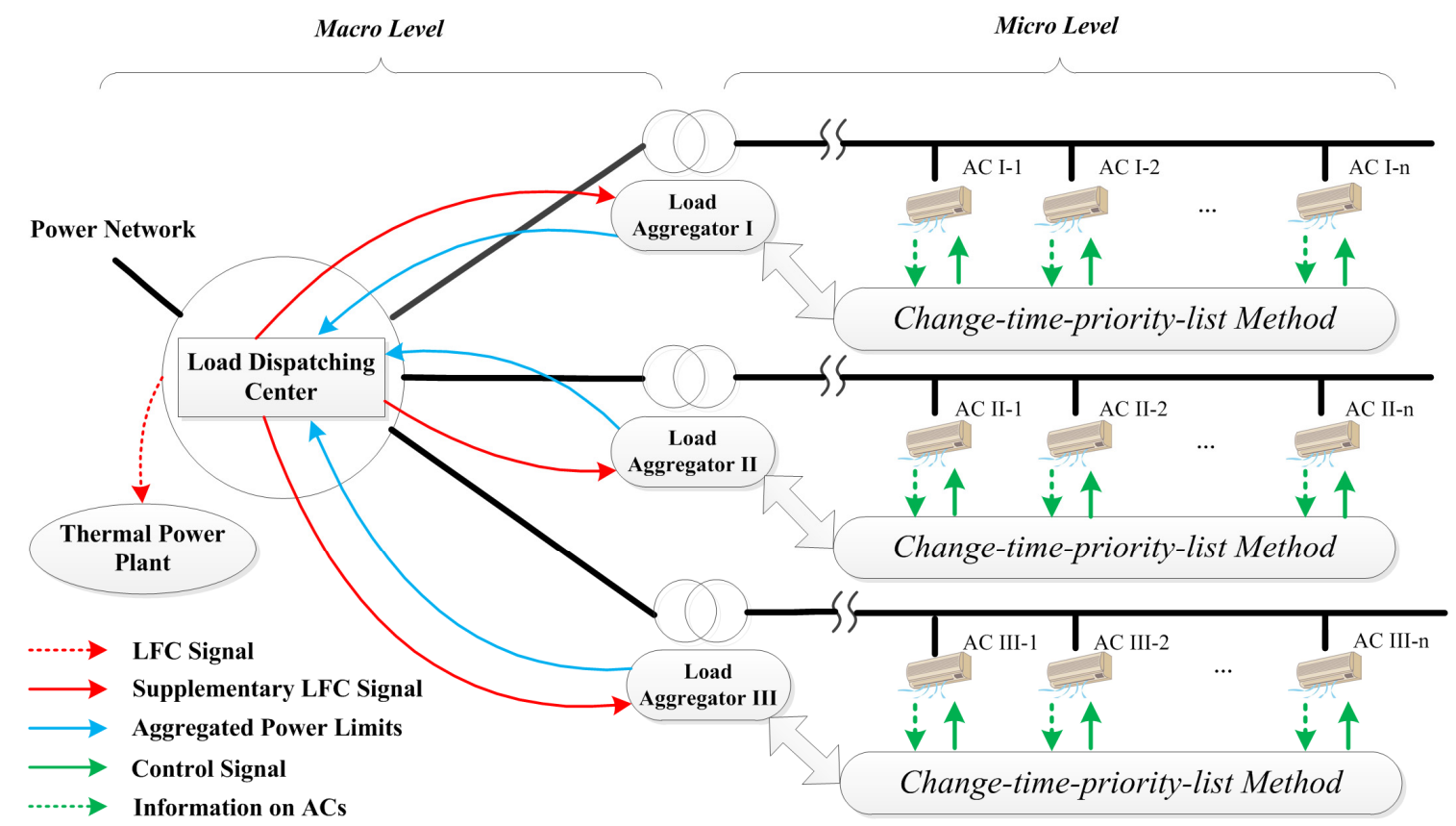

Figure 1. The bi-level control framework of combining the supplementary load frequency control (LFC) with the traditional LFC.

\subsection{Thermal Dynamic Models of a Single Air Conditioner}

One critical step of AC power consumption simulation is how to accurately simulate thermal dynamic behaviors. This part mainly introduces the ETP model and its simplified version.

The ETP model is suited for simulating the heat exchange of residential and small commercial buildings. The construction of the model is presented in Figure 2. $P$ is the AC power $(\mathrm{kw}) ; \eta$ is the AC load efficiency; $\eta P$ is the heating/cooling rate for heating, ventilation and air conditioning (HVAC) unit $(\mathrm{W}) ; C_{\mathrm{a}}$ is the air thermal capacitance $\left(\mathrm{J} /{ }^{\circ} \mathrm{C}\right) ; C_{\mathrm{m}}$ is the mass thermal capacitance $\left(\mathrm{J} /{ }^{\circ} \mathrm{C}\right) ; T_{\text {out }}$ is outdoor temperature $\left({ }^{\circ} \mathrm{C}\right) ; T_{\text {in }}$ is indoor temperature $\left({ }^{\circ} \mathrm{C}\right) ; T_{\mathrm{m}}$ is indoor mass temperature $\left({ }^{\circ} \mathrm{C}\right)$.

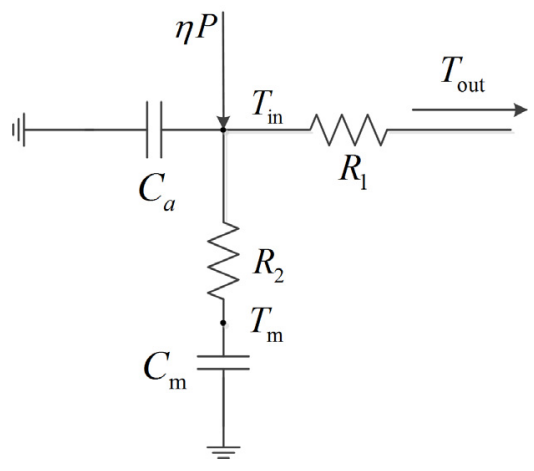

Figure 2. Equivalent thermal parameters (ETP) model of a single air-conditioning unit. 
As discussed in [27-30], the ETP model can be described by a simplified first-order model to fit the indoor temperature curve of a detailed heat exchange model. The simplified model is presented in Equations (1) and (2), in which the indoor temperature $T_{\text {in }}$ could be calculated as:

$$
\begin{gathered}
T_{\text {in }}^{t+1}=T_{\text {out }}^{t+1}-\left(T_{\text {out }}^{t+1}-T_{\text {in }}^{t}\right) \mathrm{e}^{-\frac{\Delta t}{R C}}, \quad s=0 \\
T_{\text {in }}^{t+1}=T_{\text {out }}^{t+1}-\eta P R-\left(T_{\text {out }}^{t+1}-\eta P R-T_{\text {in }}^{t}\right) \mathrm{e}^{-\frac{\Delta t}{R C}}, \quad s=1
\end{gathered}
$$

where $T_{\text {in }}^{t}$ denotes indoor temperature on time $t\left({ }^{\circ} \mathrm{C}\right) ; T_{\text {out }}^{t+1}$ denotes outdoor temperature on time $t+1$ $\left({ }^{\circ} \mathrm{C}\right) ; \mathrm{C}$ represents thermal capacitance $\mathrm{J} /{ }^{\circ} \mathrm{C} ; R$ refers to thermal resistance $\left({ }^{\circ} \mathrm{C} / \mathrm{W}\right)$; $s$ is a $0-1$ variable: 1 refers to $\mathrm{AC}$ open; 0 refers to $\mathrm{AC}$ closed and $\Delta t$ is the time step. Note that parameters $C$ and $R$ are curve fitting parameters that keep the simplified model producing a similar indoor temperature curve with that produced by the detailed model, and they are different from parameters shown in Figure 2.

Assume $T_{\text {set }}$ represents the temperature setpoint and $\delta$ denotes temperature deadbands. The indoor temperature limits $\left[T_{\min }, T_{\max }\right]$ could be calculated by Equations (3) and (4) where $\tau_{\mathrm{c}}$ is the control cycle; $\tau_{1}$ and $\tau_{0}$ refer to the duration of ACs on and off. Suppose ambient temperature is constant in the control cycle and $\mathrm{e}^{-\Delta t / R C}$ denotes $\varepsilon$ and plug the indoor temperature limits into Equations (1) and (2), the formula can be rewritten as:

$$
\begin{gathered}
T_{\min }=T_{\text {set }}-\delta / 2 \\
T_{\max }=T_{\text {set }}+\delta / 2 \\
T_{\max }=T_{\text {out }}\left(1-\varepsilon^{\tau_{0}}\right)+T_{\min } \varepsilon^{\tau_{0}} \\
T_{\min }=\left(T_{\text {out }}-\eta P R\right)\left(1-\varepsilon^{\tau_{1}}\right)+T_{\max } \varepsilon^{\tau_{1}} \\
\tau_{\mathrm{c}}=\tau_{0}+\tau_{1}
\end{gathered}
$$

Therefore, duration of AC on and off under certain ambient and indoor temperature limits could be calculated as:

$$
\begin{gathered}
\tau_{0}=\frac{R C}{\Delta t} \ln \left(\frac{T_{\min }-T_{\text {out }}}{T_{\max }-T_{\text {out }}}\right) \\
\tau_{1}=\frac{R C}{\Delta t} \ln \left(\frac{P R+T_{\max }-T_{\text {out }}}{P R+T_{\text {min }}-T_{\text {out }}}\right)
\end{gathered}
$$

In this simplified model, $T_{\text {out }}, T_{\text {in }}$ and $T_{\text {set }}$ are needed because they can influence the operation and the on/off state of ACs. $T_{\text {out }}$ can be obtained from meteorological station near the load aggregator, and we assume the $T_{\text {out }}$ of all the ACs belonging to the aggregator share the same value. Temperature control system [31] in AC could detect $T_{\text {in }}$ by temperature sensor and store $T_{\text {set }}$ in its memory, and these temperature parameters can be obtained through the data interface [32].

\section{Control Algorithms}

\subsection{Change-Time-Priority-List Method}

For the change-time-priority-list method, ACs are divided into two groups based on their on/off state. ACs in the "on" group are arranged in ascending order according to their change time from on to off. If it is required to reduce load, ACs with shorter change time take precedence to be turned off. Similarly, ACs in the "off" group are arranged in ascending order according to their change time from off to on. If it is required to increase load, ACs with shorter change time take precedence to be turned on. Point a in Figure 3 denotes an AC in the "on" group; while point b refers to an AC in the "off" group, with their corresponding indoor temperature being $T_{\mathrm{in}, \mathrm{a}}$ and $T_{\mathrm{in}, \mathrm{b}}$. The change time from on to off of AC on point a is $\tau_{\text {change,a, }}$ and the change time from off to on of AC on point $b$ is $\tau_{\text {change,b. }}$. 
Limits of indoor temperature are $\left[T_{\min }, T_{\max }\right]$. With all these variables taken into Equations (8) and (9), we can obtain:

$$
\begin{gathered}
\tau_{\text {change, } \mathrm{a}}=\frac{R C}{\Delta t} \ln \left(\frac{P R+T_{\text {in }, \mathrm{a}}-T_{\text {out }}}{P R+T_{\min }-T_{\text {out }}}\right) \\
\tau_{\text {change }, \mathrm{b}}=\frac{R C}{\Delta t} \ln \left(\frac{T_{\text {in }, \mathrm{b}}-T_{\text {out }}}{T_{\max }-T_{\text {out }}}\right)
\end{gathered}
$$

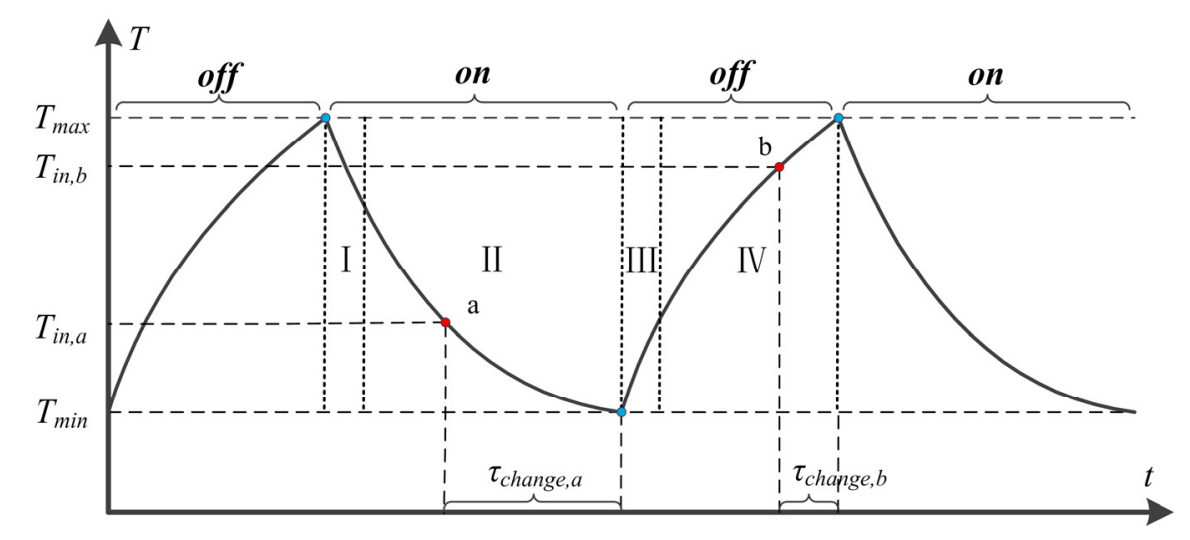

Figure 3. Thermal dynamics of an air conditioner (AC) unit.

ACs with shorter change time are close to natural state change point (the blue point in Figure 3); therefore, this paper takes priority to control ACs with shorter change time in order to minimize interference with consumers. The change-time-priority-list method takes advantage over temperature-priority-list method proposed in [27]. Firstly, temperature-priority-list method only makes sense when the temperature setpoint of each AC is the same, while the change-time-priority-list method makes it possible for consumers to select temperature setpoint freely. Secondly, change-time-priority-list method is more widely applicable. Though, for a population of homogeneous ACs, the two methods are identical, and the change-time-priority-list method performs much better than temperature-priority-list method for a population of heterogeneous ACs, which will be discussed in detail in the case study.

Four regions in Figure 3 are implemented to tell ACs which regions are suitable for control. ACs in Region I are not suitable for control because these ACs, which are just turned on, would be automatically switched on again soon after manually turned off, while ACs in Region II are appropriate for control. ACs in Region III are uncontrollable on account of their short-time closure, while ACs in Region IV are appropriate for control. Parameter $\beta$ is introduced to tell which region the $i$ th AC belongs to:

$$
\begin{aligned}
& \text { if } s_{i}=1 \text { and } \beta \leqslant \frac{\tau_{\text {change }, i}}{\tau_{1}} \leqslant 1, i \in \text { region I } \\
& \text { if } s_{i}=1 \text { and } 0 \leqslant \frac{\tau_{\text {change }, i}}{\tau_{1}} \leqslant \beta, i \in \text { region II } \\
& \text { if } s_{i}=0 \text { and } \beta \leqslant \frac{\tau_{\text {change }, i}}{\tau_{0}} \leqslant 1, i \in \text { region III } \\
& \text { if } s_{i}=0 \text { and } 0 \leqslant \frac{\tau_{\text {change, }}}{\tau_{0}} \leqslant \beta, i \in \text { region IV }
\end{aligned}
$$

\subsection{Combining with the Traditional Load Frequency Control}

The frequency response model of the power system is shown in Figure 4. Supplement LFC provided by aggregated ACs is integrated with conventional LFC, which is the model of the simulation in this paper. The detailed parameters of this model are summarized in Table 1. 


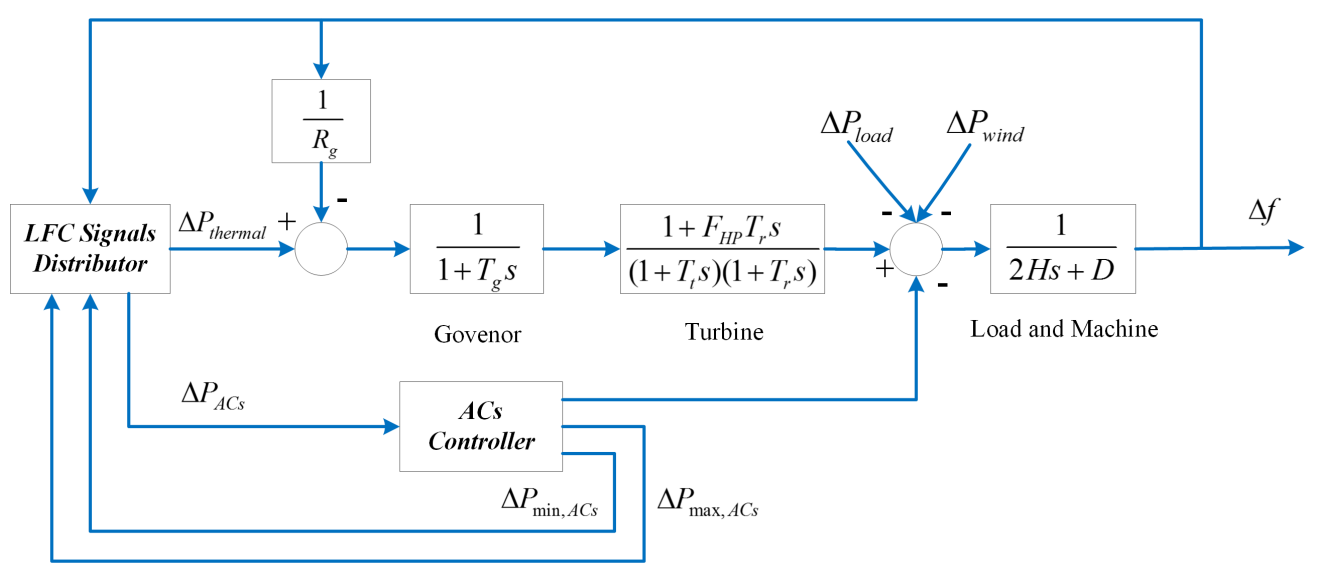

Figure 4. Simulation system for combining supplement LFC with the traditional LFC.

Table 1. Parameters of simulation system.

\begin{tabular}{ccc}
\hline Parameters & Description & Unit \\
\hline$s$ & Laplace operator & - \\
$T \mathrm{~g}$ & Deviation of system frequency & $\mathrm{Hz}$ \\
$F_{\mathrm{HP}}$ & Speed governor time constant & $\mathrm{s}$ \\
$T_{\mathrm{r}}$ & Power fraction of the high pressure & $\mathrm{p} . \mathrm{u}$. \\
$T_{\mathrm{t}}$ & turbine section & $\mathrm{s}$ \\
$H$ & Reheat time constant & $\mathrm{s}$ \\
$D$ & Turbine time constant & $\mathrm{p} \cdot \mathrm{u} \cdot \mathrm{s}$ \\
$R \mathrm{~g}$ & Inertia constant of generators and motors & $\mathrm{p} \cdot \mathrm{u} \cdot / \mathrm{Hz}$ \\
$\Delta P_{\text {load }}$ & Load-damping constant & $\mathrm{Hz} / \mathrm{p} \cdot \mathrm{u}$. \\
$\Delta P_{\text {wind }}$ & Speed droop & $\mathrm{MW}$ \\
$\Delta P_{\text {thermal }}$ & Load fluctuation & $\mathrm{MW}$ \\
$\Delta P_{A C s}$ & Wind power output fluctuation & $\mathrm{MW}$ \\
$\Delta P_{\max , A C s}$ & LFC signals for thermal plant & $\mathrm{MW}$ \\
$\Delta P_{\min , A C s}$ & LFC signals for aggregated ACs & $\mathrm{MW}$ \\
& The upper limit of ACs' power changes & $\mathrm{MW}$ \\
\hline
\end{tabular}

The simulation system is composed of two parts: one is the frequency response model of the power system including governor block, turbine block, load and machine block and $1 / R_{\mathrm{g}}$ block (see $[5,6])$; the other are the two blocks proposed in this paper-LFC signal distributor and AC controller.

LFC signals distributor is implemented to calculate the LFC signal of thermal plant and aggregated ACs (Figure 5). Signal distribution is realized through saturation dynamic block and $\Delta P_{\max , A C s} \Delta P_{\min , A C s}$ sent back from ACs controller.

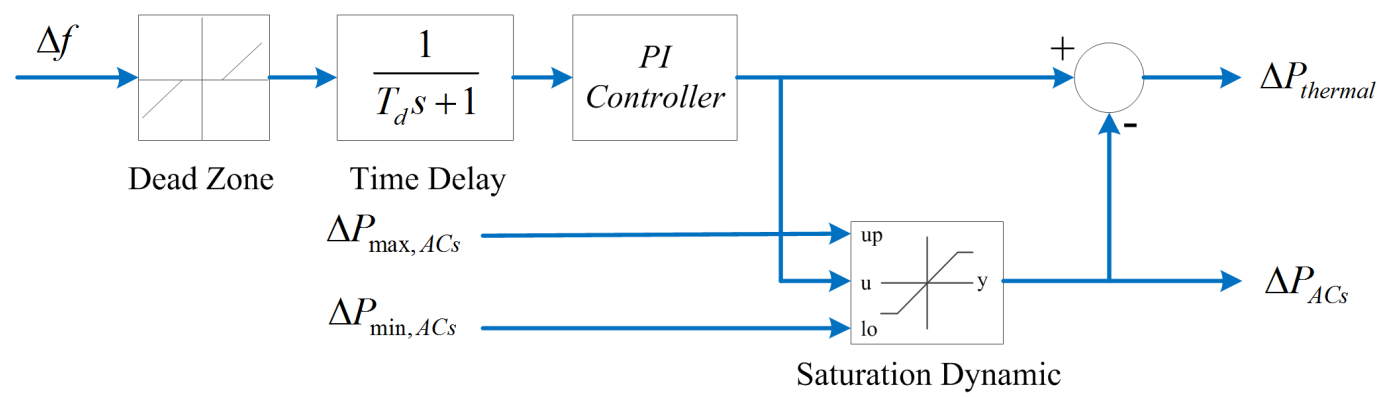

Figure 5. Block diagram of the LFC signal distributor. Proportional-integral: PI. 
AC controller block is realized through the MATLAB-function. The ACs under change-time-priority-list method are prioritized in ascending order based on their change time, i.e., ACs with shorter change time would be at the top of the list to be controlled. At the same time, the impact of AC natural on/off state change on the control results is also taken into consideration. Specific procedures are as follows.

Step 1: The change time of individual AC $\tau_{\text {changetime, } i}^{t}$ and the aggregated load of $N$ ACs without control on time $t$ are calculated by formula in Equations (10) or (11), in which $s_{i}^{t}$ denotes the estimated $\mathrm{AC}$ on/off state on time $t$ and $R_{i}, C_{i}, P_{i}$ denote AC characteristic parameters.

$$
P_{\mathrm{ACs}, \text { uncontrolled }}^{t}=\sum_{i=1}^{N} P_{i} \times s_{i}^{t}
$$

Step 2: Assume $\Delta t$ is the time step of AC control. For ACs meet $\tau_{\text {changetime }, i}^{t} \leqslant \Delta t$ and $s=1$, their change time is less than time step; therefore, these ACs would automatically be switched from on to off in this period. Assume the set of these ACs is $N_{+}^{t}$, the total power is:

$$
P_{+, A C s}^{t}=\sum_{i=1}^{N_{+}^{t}} P_{i}
$$

Step 3: For ACs meet $\tau_{\text {changetime }, i}^{t} \leqslant \Delta t$ and $s=0$, their change time is also less than time step; therefore, these ACs would automatically be switched from off to on in this period. Assume the set of these ACs is $N_{-}^{t}$, the total power is:

$$
P_{-, A C S}^{t}=\sum_{i=1}^{N_{-}^{t}} P_{i}
$$

Step 4: Assume the frequency fluctuation signal on time $t$ is $\Delta f^{t}$ and the limits of aggregated AC load is $\Delta P_{\text {max }, A C_{S}}^{t}$ and $\Delta P_{\min , A C_{S}}^{t} \Delta P_{\text {thermal }}^{t}$ and $\Delta P_{A C_{S}}^{t}$ could be calculated by LFC distributor block. Note that positive $\Delta P_{\text {thermal }}^{t}$ indicates that the output of generators needs to be increased. While positive $\triangle P_{A C S}^{t}$ indicates that aggregators are needed to turn off ACs so as to decrease load.

- If $\Delta P_{A C s}^{t}>\left(P_{+, A C s}^{t}-P_{-, A C s}^{t}\right)$, go to Step 5;

- If $\Delta P_{A C_{S}}^{t}<\left(P_{+, A C S}^{t}-P_{-, A C S}^{t}\right)$, go to Step 6;

- If $\Delta P_{A C S}^{t}=\left(P_{+, A C S}^{t}-P_{-, A C s}^{t}\right)$, go to Step 7 .

Step 5: It is required to reduce load in this step. We can use Equation (13) to tell which AC belongs to Region II. Apart from the $N_{+}^{t}$ ACs in Step 2, there are $N_{\text {II }}^{t}-N_{+}^{t}$ controllable ACs in total. Work out the change-time-priority-list of these ACs and select several ACs from the top of the list. Assume the set of these selected ACs is $M_{+}^{t}$, which should make Equation (19) hold:

$$
\left(P_{+, A C s}^{t}-P_{-, A C S}^{t}\right)+\sum_{i=1}^{M_{+}^{t}} P_{i} \leqslant \Delta P_{A C s}^{t}<\left(P_{+, A C s}^{t}-P_{-, A C s}^{t}\right)+\sum_{i=1}^{M_{+}^{t}+1} P_{i} \text { or } M_{+}^{t}=N^{t}-N_{+}^{t}
$$

Step 6: It is required to increase load in this step. ACs in region IV are determined through Equation (15): apart from the $N_{-}^{t}$ ACs in Step 3, there are $N_{\mathrm{IV}}^{t}-N_{-}^{t}$ ACs in total. Work out the change-time-priority-list of these ACs and select several from the top of the list as $M_{-}^{t}$, we can get:

$$
\left(P_{+, A C s}^{t}-P_{-, A C S}^{t}\right)-\sum_{i=1}^{M_{-}^{t}} P_{i} \geqslant \Delta P_{A C S}^{t}>\left(P_{+, A C S}^{t}-P_{-, A C s}^{t}\right)-\sum_{i=1}^{M_{-}^{t}+1} P_{i} \text { or } M_{-}^{t}=N^{t}-N_{-}^{t}
$$


Step 7: No more operations are needed except for ACs belong to set $N_{-}^{t}$ and $N_{+}^{t}$. Turn off ACs in $N_{+}^{t}$ and turn on ACs in $N_{-}^{t}$.

Step 8: Calculate the controlled AC power on time $t$ :

$$
P_{A C s, \text { controlled }}^{t}=P_{A C s, \text { uncontrolled }}^{t}+\left(P_{+, A C s}^{t}-P_{-, A C s}^{t}\right)-\sum_{i=1}^{M_{+}^{t}} P_{i}\left(\text { or }+\sum_{i=1}^{M_{-}^{t}} P_{i}\right)
$$

Step 9: This step aims to estimate the value of several variables on time $t+1$. According to the control result in Steps 5-7, $s_{i}^{t+1}$ could be deduced by $s_{i}^{t}$ and the indoor temperature on time $t+1$ could be calculated by Equations (1) and (2). Equations (10)-(15) could be used to locate ACs in each region. Similarly, the upper and lower limits of aggregated power on time $t+1$ could be estimated by:

$$
\begin{aligned}
& P_{\max , A C S}^{t+1}=P_{\text {uncontrolled }}^{t+1}+\Delta P_{\max , A C s}^{t+1}=P_{\text {uncontrolled }}^{t+1}+\sum_{i=1}^{N^{t+1}} P_{i} \\
& P_{\text {min, } A C S}^{t+1}=P_{\text {uncontrolled }}^{t+1}+\Delta P_{\text {min, } A C S}^{t+1}=P_{\text {uncontrolled }}^{t+1}-\sum_{i=1}^{N^{t+1}} P_{i}
\end{aligned}
$$

It could be concluded that the upper limit of aggregated load could be obtained by turning on aggregated ACs in region IV, while the lower limit of aggregated load could be obtained by turning off aggregated ACs in region II.

Figure 6 demonstrates the process from Steps 1 to 9. Aggregators need to estimate the uncontrolled aggregated $\mathrm{AC}$ load $P_{\mathrm{ACs} \text {, uncontrolledand }}^{t}$ the limits of aggregated $\mathrm{AC}$ load $P_{\max , A C s}^{t}$ and $P_{\min , A C S}^{t}$ on time $t-1 . P_{+, A C s}^{t}$ and $P_{-, A C S}^{t}$ is determined by Steps 2 and 3. Steps 4-7 aim to select ACs to be controlled and calculate the controlled aggregated AC load $P_{A C s, \text { controlled. According to this }}^{t}$ value, uncontrolled aggregated AC load on time $t+1 P_{A C s, \text { uncontrolled }}^{t+1}$ and the limits of aggregated AC loadon time $t+1 P_{\max , A C_{S}}^{t+1}$ and $P_{\min , A C_{S}}^{t+1}$ could be estimated.

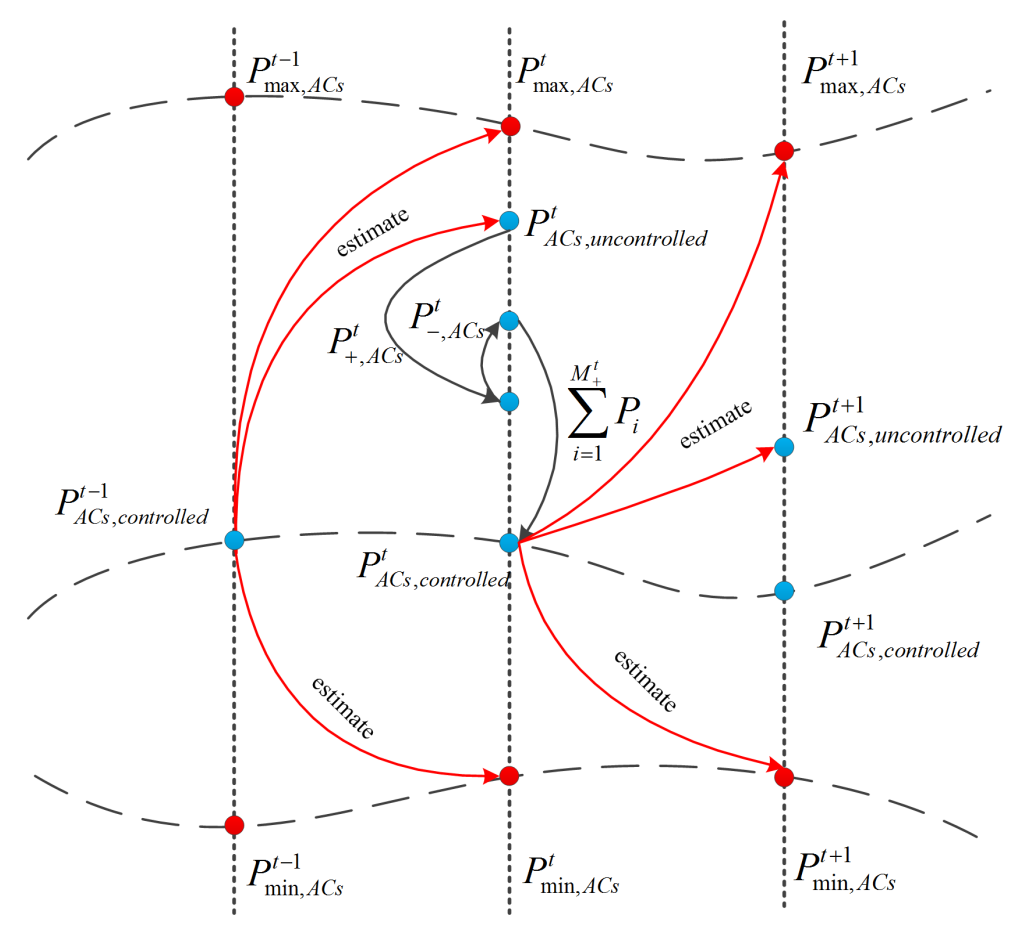

Figure 6. Schematic diagram of the process from Steps 1 to 9. 


\section{Simulation and Discussion}

\subsection{Simulation Setting}

The simulation system in Figure 5 has been discussed previously, and the detailed parameters of the power grid model are summarized in Table 2 . In this single-area power grid, $5 \%$ of maximum load capacity is reserved for the governor regulation control. Power fluctuation of the system covers two parts: load fluctuation of the entire load except ACs (Figure 7) and output fluctuation of wind farm (Figure 8). The whole simulation is based on real historical data.

Table 2. Parameters of power grid model.

\begin{tabular}{ccc}
\hline Parameters & Unit & Value \\
\hline Maximum load capacity & MVA & 100 \\
Speed governor time constant & $\mathrm{s}$ & 0.2 \\
Power fraction of the high pressure & p.u. & 0.3 \\
turbine section & $\mathrm{s}$ & 7 \\
Reheat time constant & $\mathrm{s}$ & 0.3 \\
Turbine time constant & p.u. $\cdot \mathrm{s}$ & 5 \\
Inertia constant of generators and motors & p.u. $/ \mathrm{Hz}$ & 1 \\
Load-damping coefficient & Hz/p.u. & 0.05 \\
Speed droop & &
\end{tabular}

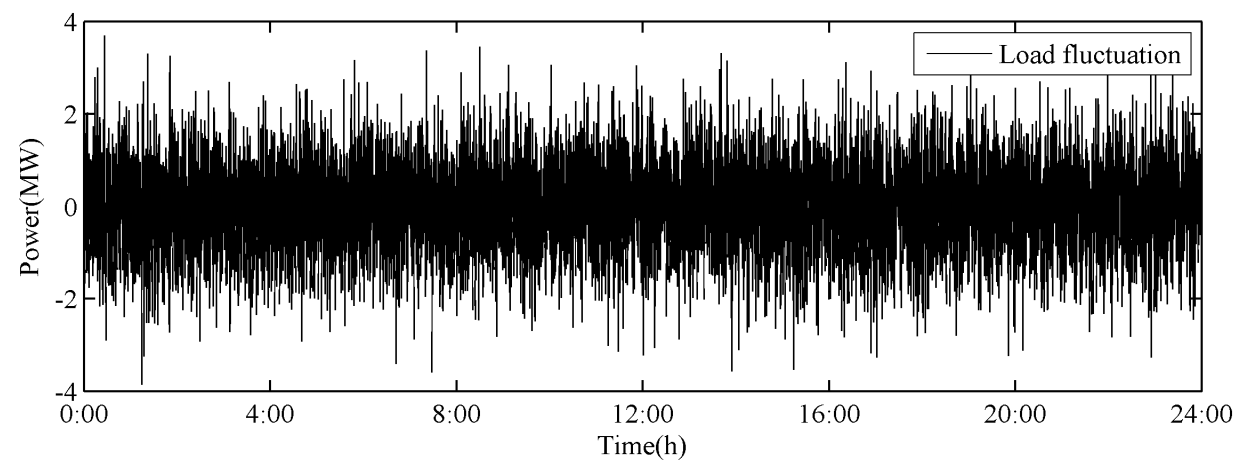

Figure 7. Load fluctuation of a whole day with 10 s intervals.

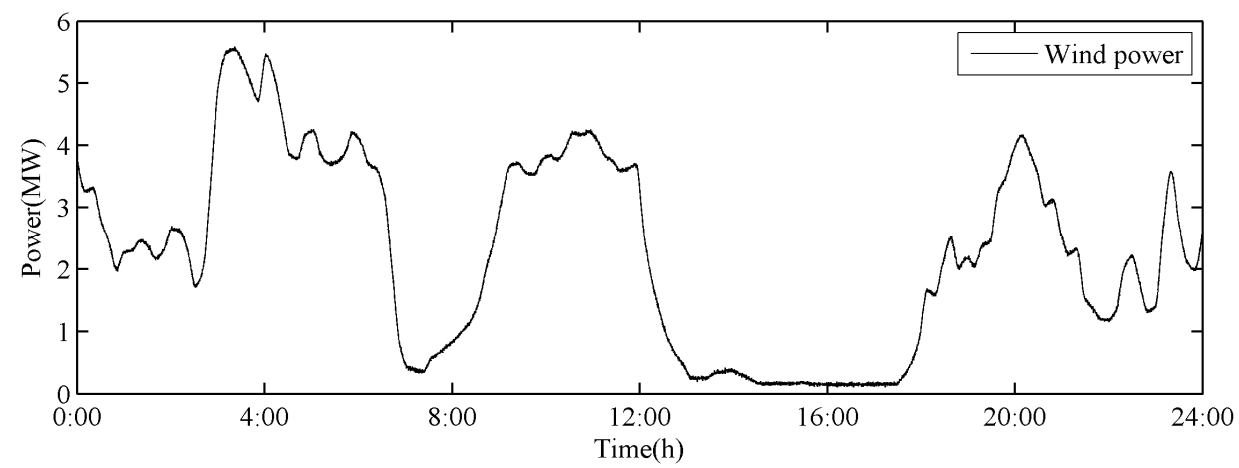

Figure 8. Wind power of a whole day with $10 \mathrm{~s}$ intervals.

In China, the customers usually start working at 9 a.m. and return home at 5 p.m. During this period, ACs could be kept on. Therefore, the simulation time in this paper is set to be 9 a.m. to 5 p.m. Assume load aggregator has signed contracts to involve 6000 AC-owners in the LFC program in this period. Ambient temperature is shown in Figure 9. Parameters of ACs in the aggregated group are 
shown in Table 3, in which parameters $R, C$ and $P$ all follow lognormal distribution, as mentioned in $[9,33]$.

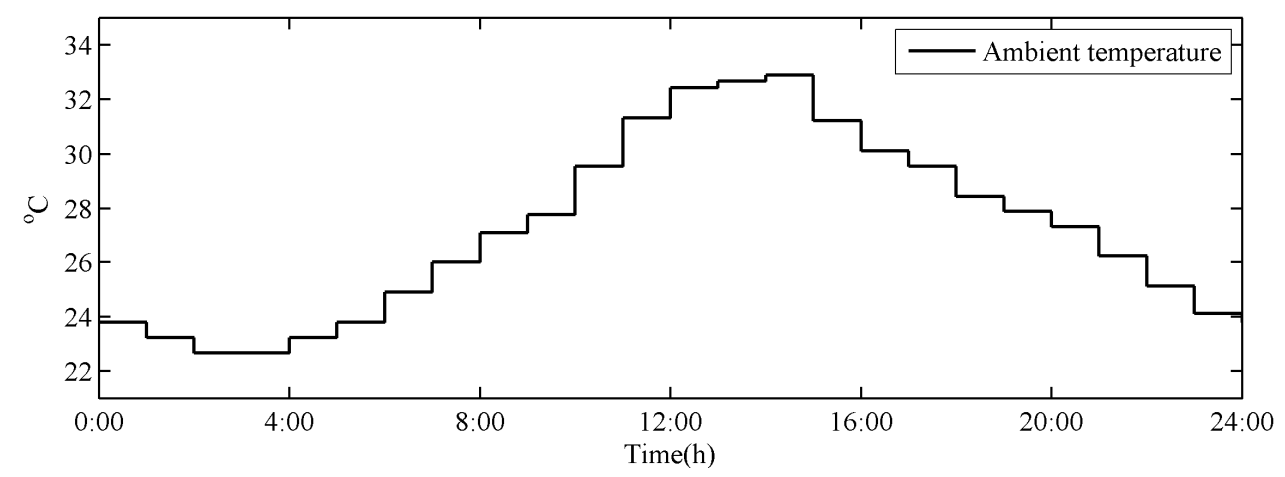

Figure 9. Ambient temperature.

Table 3. Parameters of aggregated ACs.

\begin{tabular}{ccc}
\hline Parameters & Description & Value \\
\hline$R$ & $\begin{array}{c}\text { Equivalent thermal resistance (log-normally distributed with } \\
\left.\text { mean } \mu_{R} \text { and standard deviation } \sigma_{P} \times \mu_{R}\right)\end{array}$ & - \\
$C$ & $\begin{array}{c}\text { Equivalent heat capacity (log-normally distributed with } \\
\left.\text { mean } \mu_{\mathrm{C}} \text { and standard deviation } \sigma_{P} \times \mu_{\mathrm{C}}\right)\end{array}$ & - \\
$P$ & $\begin{array}{c}\text { Equivalent thermal power }(\text { log-normally distributed with } \\
\left.\text { mean } \mu_{P} \text { and standard deviation } \sigma_{P} \times \mu_{P}\right)\end{array}$ & - \\
$\mu_{R}$ & Mean value for log-normally distributed of $R$ & $2{ }^{\circ} \mathrm{C} / \mathrm{kW}$ \\
$\mu_{C}$ & Mean value for log-normally distributed of $\mathrm{C}$ & $2 \mathrm{kWh} /{ }^{\circ} \mathrm{C}$ \\
$\mu_{P}$ & Mean value for log-normally distributed of $P$ & $5.6 \mathrm{~kW}$ \\
$\sigma_{P}$ & Standard deviation of lognormal distributions, as a fraction & 0.2 \\
$\eta$ & of the mean value, for $R, C$, and $P$ & 2.5 \\
$T_{\text {ave }}$ & Load efficiency & $31^{\circ} \mathrm{C}$ \\
$T_{\text {set }}$ & Average ambient temperature & $23^{\circ} \mathrm{C}$ \\
$\delta$ & temperature setpoint & $4{ }^{\circ} \mathrm{C}$ \\
$T_{\max }$ & temperature deadband & $25^{\circ} \mathrm{C}$ \\
$T_{\min }$ & the upper limit of indoor temperature & $20^{\circ} \mathrm{C}$ \\
\hline
\end{tabular}

The five cases in this simulation are demonstrated in Table 4. Case A, the base case, aims to verify the effectiveness and robustness of the proposed model on reducing system power fluctuations. Case $\mathrm{B}$ has testified the superiority of the change-time-priority-list method through comparison with the methods proposed in [27]. Case C summarizes the impact of AC control dead zone parameter $\beta$ on simulation result. Case $\mathrm{D}$ tests the performance of the algorithm using three ambient temperature profiles. Case E compares simulation results under three deadband settings. Two indices would be implemented in the analysis-root mean square (RMS) values of frequency to measure system frequency fluctuation and root mean square errors (RMSEs) to evaluate the deviations between the actual power of aggregated ACs and the LFC signal:

$$
\begin{gathered}
R M S=\sqrt{\frac{\sum_{t=1}^{N_{\text {sim }} f_{t}^{2}}}{N_{\text {sim }}}} \\
R M S E=\sqrt{\frac{\sum_{t=1}^{N_{\text {sim }}}\left(\mathrm{P}_{A C, \text { controlled }}^{t}-\mathrm{P}_{\mathrm{LFC}}^{t}\right)^{2}}{N_{\text {sim }}}}
\end{gathered}
$$


In this paper, we simulated in MATLAB 2010b in Windows 7, a processor Intel Corei3-4150M CPU@3.50GHz, memory $4.00 \mathrm{~GB}$, based on x86 processor 32 bit operating system.

Table 4. Case introduction.

\begin{tabular}{ccccc}
\hline Case name & Control algorithm & $\begin{array}{c}\text { AC control dead } \\
\text { zone parameter }\end{array}$ & $\begin{array}{c}\text { Average ambient } \\
\text { temperature }\end{array}$ & $\begin{array}{c}\text { Temperature } \\
\text { deadband }\end{array}$ \\
\hline Case A & Change-time-priority-list method & 0.9 & 31 & 4 \\
Case B & Temprature-priority-list method & 0.9 & 31 & 4 \\
Case C & Change-time-priority-list method & $\mathbf{0 . 5 / 0 . 7 / 0 . 9}$ & 31 & 4 \\
Case D & Change-time-priority-list method & 0.9 & $\mathbf{2 5 / 2 7 / 2 9 / 3 1 / 3 3}$ & 4 \\
Case E & Change-time-priority-list method & 0.9 & 31 & $\mathbf{2 / 4 / 6}$ \\
\hline
\end{tabular}

\subsection{Case A: Response to Load Frequency Control Signals}

The simulation results of Case A are shown in Figure 10. Frequency fluctuation, as shown in Figure 10a, has significantly reduced as aggregated AC load incorporated in control, which verifies the effectiveness of the proposed method. Figure 10b demonstrates aggregated AC power limits, uncontrolled aggregated AC power as well as the actual output of aggregated AC. The power curve of uncontrolled AC is the natural operation curve of the 6000 ACs with temperature setpoint given by customers. It degrades sharply at about 9:30 in that most ACs are turned off with relatively low ambient temperature. The curve after 9:30 is similar to the temperature curve. The power limits of $\mathrm{ACs}$ are the aggregated $\mathrm{AC}$ output limits $\Delta P_{\max , A C s}^{t}$ and $\Delta P_{\min , A C s}^{t}$ in Figure 5. It could be observed that the power of controlled $\mathrm{AC}$ is restrained within this range. Figure 10c shows that all the indoor temperature varies from $21^{\circ} \mathrm{C}$ to $25^{\circ} \mathrm{C}$, not beyond the limits set by customers. Figure $10 \mathrm{~d}$ summarizes the impact of control method on the number of cycles of ACs. The number of nature cycles of ACs is around 10-20 when the ACs are uncontrolled. To trace LFC signal, the number of cycles increase, but it is still restrained under 30 .

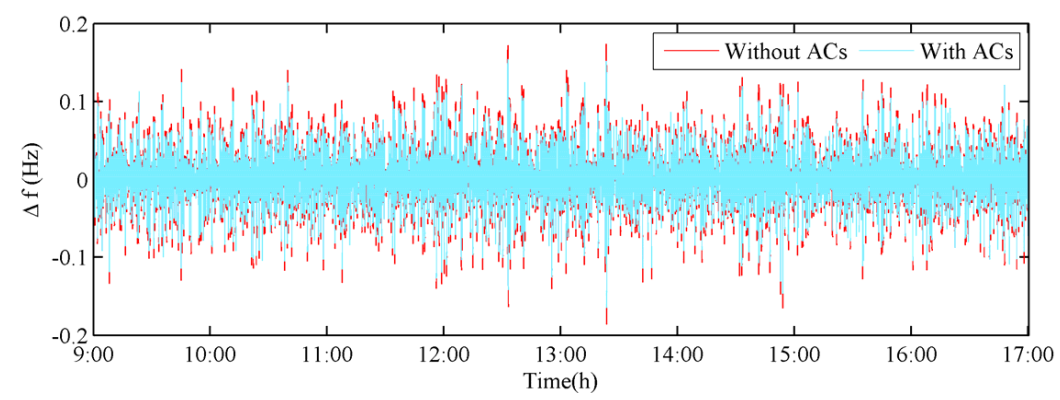

(a)

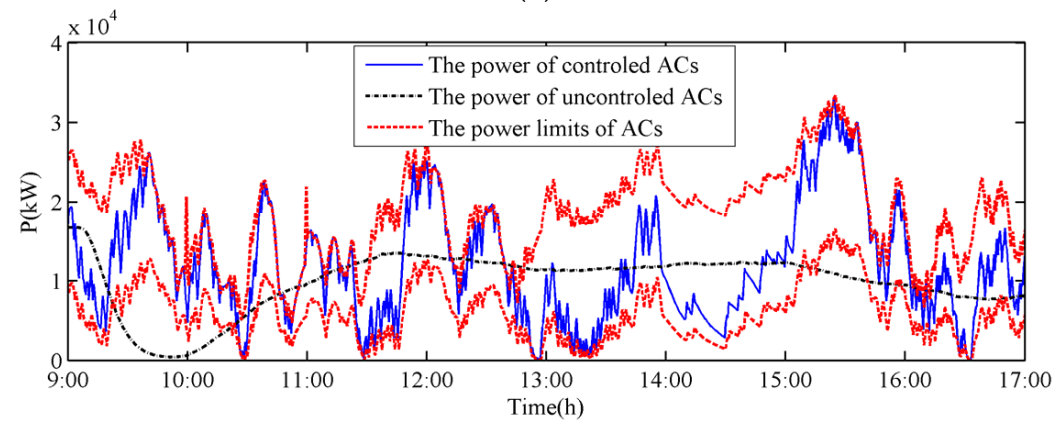

(b)

Figure 10. Cont. 


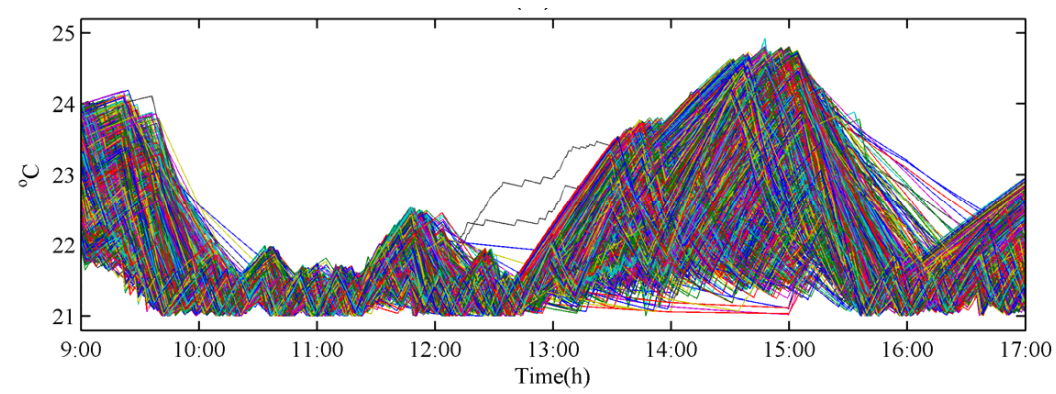

(c)

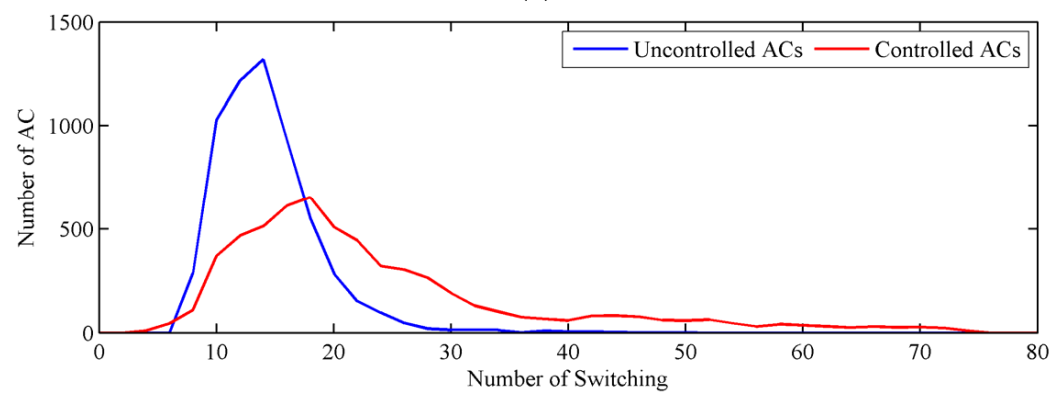

(d)

Figure 10. Simulation results of combining ACs with the traditional LFC by change-time-priority -list method: (a) frequency deviation; (b) actual power consumption of controlled ACs; (c) room temperature profiles in 6000 residential houses; and (d) AC cycles in simulation period.

\subsection{Case B: Compared with Temperature-Priority-List Method}

In Case B, temperature-priority-list method [27] is used for simulation. Table 5 shows the impact of different methods on quality of frequency deviation, which is judged by the maximum value (MAX), minimum value (MIN), and RMS value of frequency deviation. It could be seen that system frequency quality is always improved by combining aggregated ACs with the traditional LFC. However, Case B possesses wider range of frequency deviation than that in Case A and RMS value in Case B is also higher than that in Case A. Apparently, quality of frequency deviation in Case B is not that fine as in Case A. Figure 11 shows the impact of different methods on ACs cycles. With temperature-priority-list method involved in the simulation, the average cycles of ACs increases to about 40 and the cycle times are mainly distributed in region 20-60, which demonstrates greater impact of this control method on consumers. AC parameters of each consumer are disparate so that the state change time of each AC differs from others in spite of the same indoor temperature. That is why ordering the ACs by state change time could guarantee minimum impact on consumers.

Table 5. Impact of different methods on quality of frequency deviation. Maximum value: MAX; minimum value: MIN; root mean square: RMS.

\begin{tabular}{cccc}
\hline Control method & MAX (Hz) & MIN (Hz) & RMS (Hz) \\
\hline Without ACs & 0.1736 & -0.1861 & 0.0395 \\
With ACs by change-time-priority-list method (Case A) & 0.1484 & -0.1633 & 0.0362 \\
With ACs by temperature-priority-list method (Case B) & 0.154 & -0.1645 & 0.0363 \\
\hline
\end{tabular}




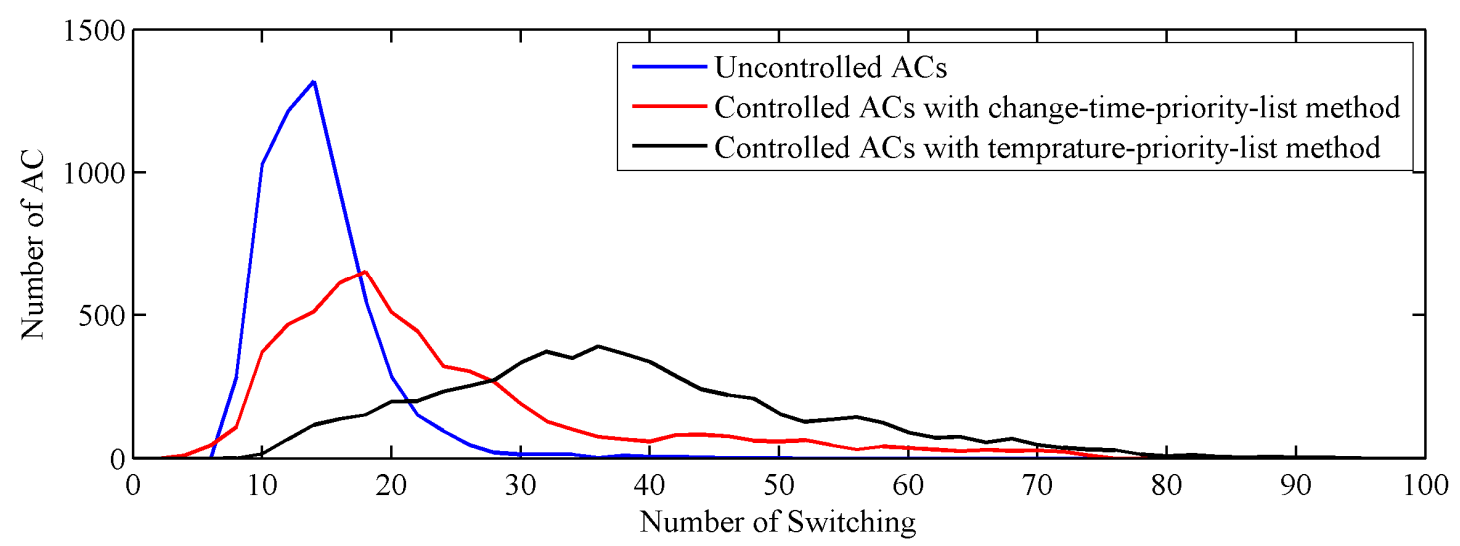

Figure 11. Impact of different methods on AC cycles.

\subsection{Case C: Impacts of Parameter $\beta$ on Results}

Parameter $\beta$ directly decides which region the ACs belong to. According to Equations (12)-(15), with the increase of $\beta$, the area of region II and IV would increase while the area of region I and III would decrease, and vice versa. That is to say, parameter $\beta$ closely relates to the quantity of controlled ACs and directly influences the power adjustment capability of the aggregated ACs. Table 6 demonstrates the impact of different $\beta$ on quality of frequency deviation. When $\beta$ varies from 0.5 to 0.9 , the minimum value of frequency increases from -0.1721 to -0.1622 ; the maximum value of frequency decreases from 0.1611 to 0.1484 ; the RMS value also decreases. Therefore, it could be concluded that, with the increase of $\beta$, more ACs are involved in the control and the quality of frequency deviation is improved.

Table 6. Impact of different $\beta$ on quality of frequency deviation.

\begin{tabular}{cccc}
\hline $\boldsymbol{\beta}$ & MAX (Hz) & MIN (Hz) & RMS (Hz) \\
\hline 0.5 & 0.1611 & -0.1721 & 0.0366 \\
0.7 & 0.1566 & -0.1682 & 0.0363 \\
0.9 & 0.1484 & -0.1633 & 0.0362 \\
\hline
\end{tabular}

Figure 12 demonstrates the impact of different $\beta$ on tracking LFC signals. As mentioned, RMSE is implemented to evaluate the deviations between the actual power of aggregated ACs and the LFC signal, and the smaller value of RMSE means smaller difference value and more accurate signal tracking. It could be summarized that, with the increase of $\beta$ value, the RMSE value decreases and the signal tracking performance goes better.

Figure 13 illustrates that parameter $\beta$ has significant influence on indoor temperature curve. When $\beta=0.5$, indoor temperature curve resembles the temperature curve without any control, for the reason that the quantity of controlled ACs is quite small and other ACs operate under their natural law. The blue solid line in Figure 14 demonstrates that this $\beta$ value brings consumers less impacts. With the increase of $\beta$ value, all ACs are quickly synchronized (see Figure 13c) and frequently turned on or off (Figure 14) to follow the control signal. To conclude, larger $\beta$ value could guarantee better quality of frequency deviation but, at the same time, it also results in more influence to consumers. 

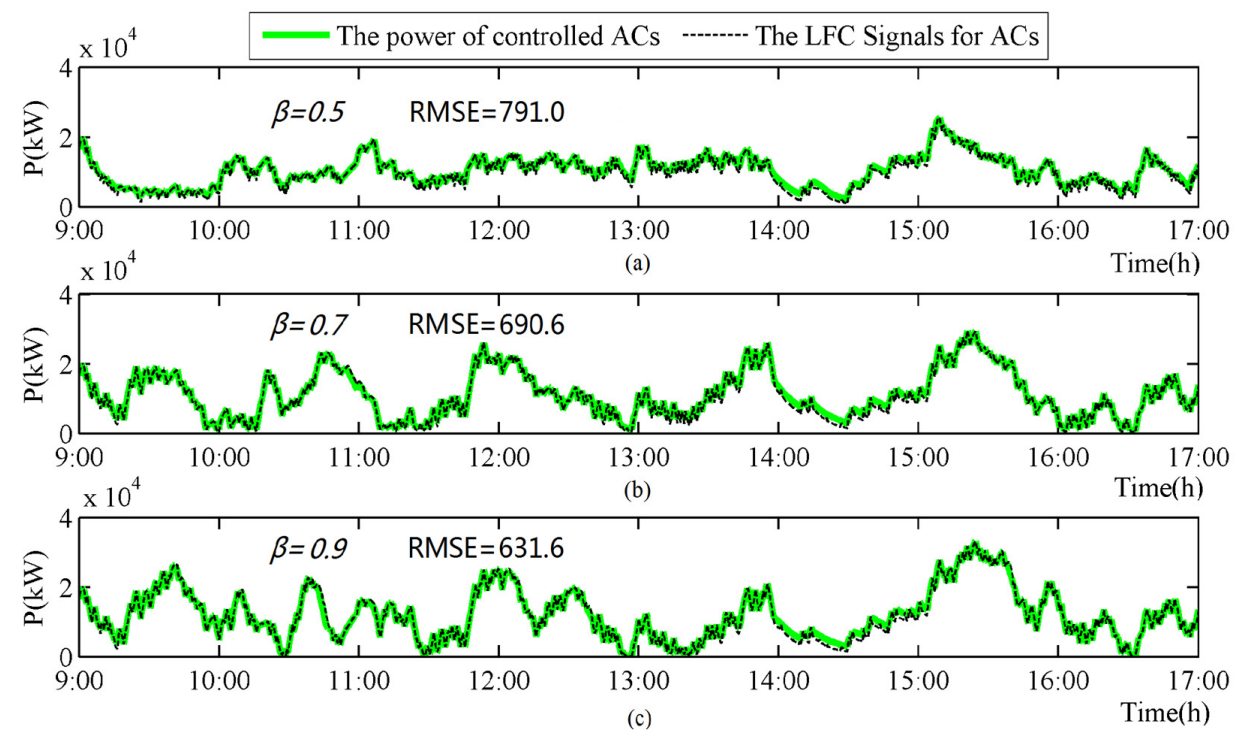

Figure 12. Impact of different $\beta$ on tracking LFC signals. (a) $\beta=0.5$; (b) $\beta=0.7$; (c) $\beta=0.9$.
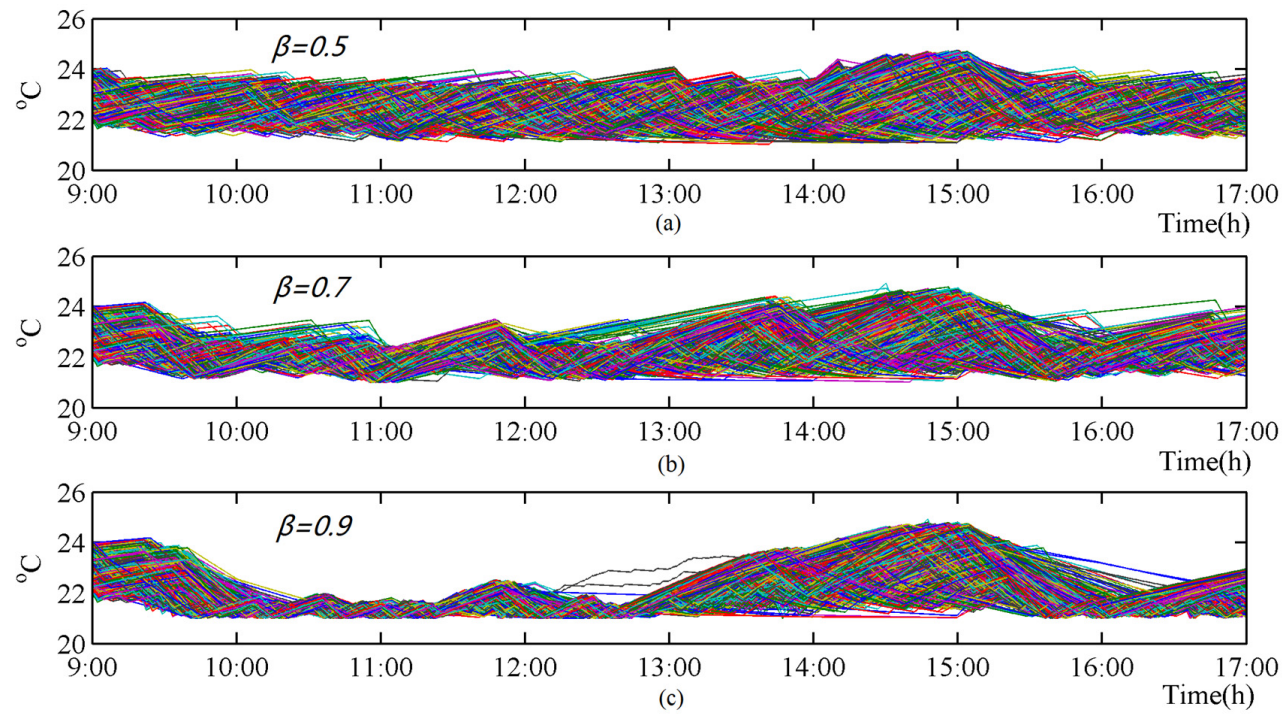

Figure 13. Impact of different $\beta$ on room temperature profiles. $(\mathbf{a}) \beta=0.5 ;(\mathbf{b}) \beta=0.7 ;(\mathbf{c}) \beta=0.9$.

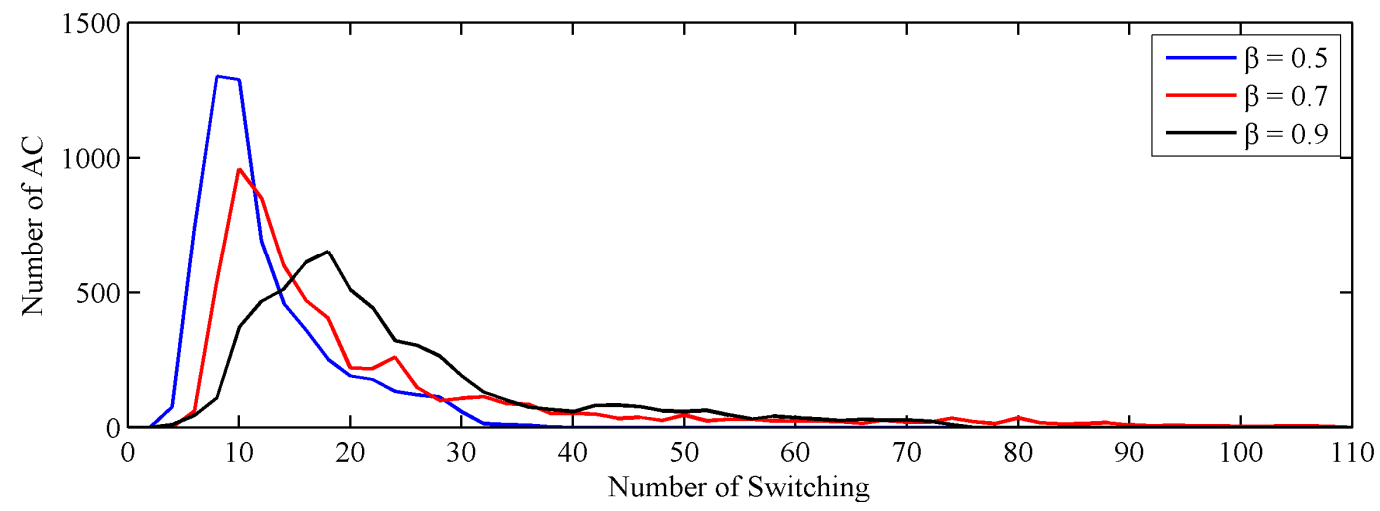

Figure 14. Impact of different $\beta$ on $A C$ cycles. 


\subsection{Case D: Impacts of Ambient Temperature Changes on Results}

In this case, we tested the performance of the algorithm using five ambient temperature profiles: $T_{\text {ave }}=25^{\circ} \mathrm{C}, 27^{\circ} \mathrm{C}, 29^{\circ} \mathrm{C}, 31^{\circ} \mathrm{C}$ and $33^{\circ} \mathrm{C}$ as shown in Figure 15.

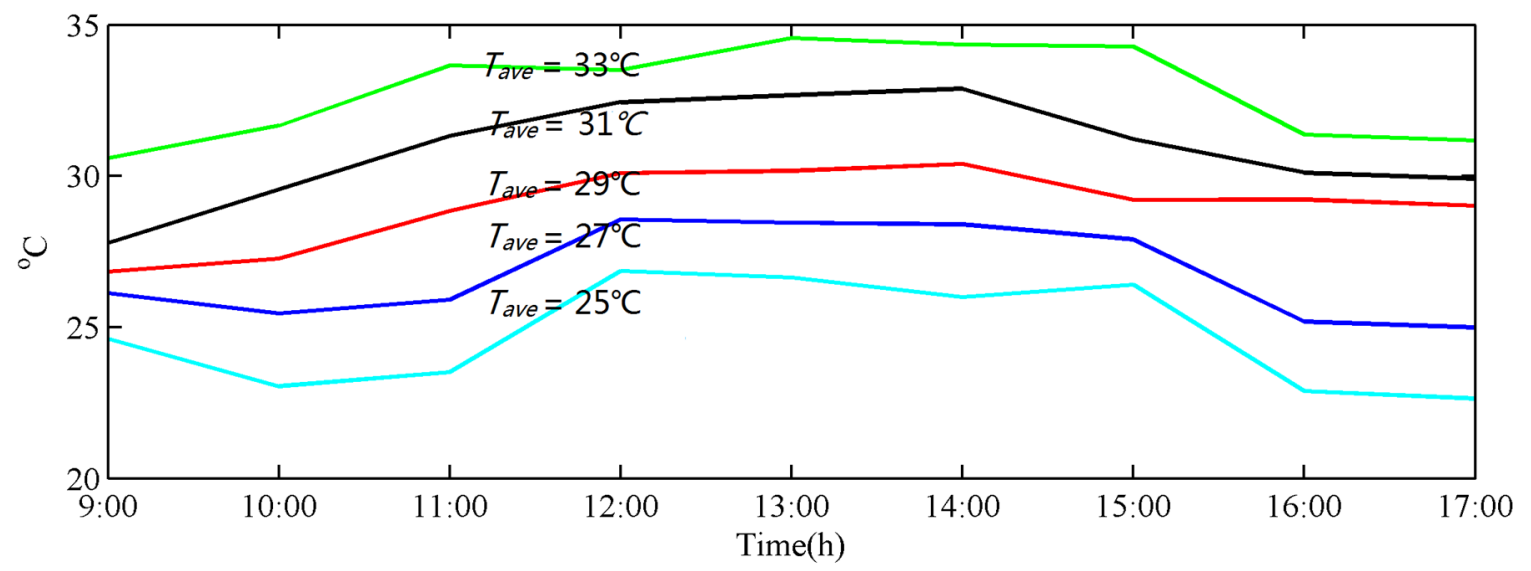

Figure 15. Different ambient temperature profiles.

Overall, we have obtained better simulation results, both on frequency deviation quality (Table 7) and LFC signal tracking quality (Figure 16) with average ambient temperature being $29{ }^{\circ} \mathrm{C}$. Reasons are that, under lower temperature, for example, average ambient temperatures being $25^{\circ} \mathrm{C}$, most ACs are left on standby, which results in lower overall load. Even though ACs are turned on, indoor temperature will soon drop below the lower limit and ACs will be turned off again. As a result, indoor temperature distributes near the lower temperature limit (see Figure 17e), and the aggregated AC load lacks the capability of reducing load. Similarly, with high ambient temperature limit, for example $33{ }^{\circ} \mathrm{C}$, ACs keep running to restrain indoor temperature from rising. Once turned off, the temperature increased to upper temperature limit in a short time. As a result, indoor temperature distribute near the upper temperature limit (see Figure 17a), and the aggregated AC load lacks the capability of increasing load. The lack of load adjustment capability impacts the performance of simulation result.

Table 7. Impact of different ambient temperature on quality of frequency deviation.

\begin{tabular}{cccc}
\hline Average ambient temperature & MAX (Hz) & MIN (Hz) & RMS (Hz) \\
\hline $25^{\circ} \mathrm{C}$ & 0.1751 & -0.1812 & 0.373 \\
$27^{\circ} \mathrm{C}$ & 0.1421 & -0.1598 & 0.360 \\
$29^{\circ} \mathrm{C}$ & 0.1314 & -0.1562 & 0.357 \\
$31^{\circ} \mathrm{C}$ & 0.1484 & -0.1633 & 0.362 \\
$33^{\circ} \mathrm{C}$ & 0.1536 & -0.1645 & 0.364 \\
\hline
\end{tabular}

Figure 18 shows the impact of different ambient temperature on AC cycles, which clearly demonstrates that under proper ambient temperature, for example $27^{\circ} \mathrm{C}$ and $29{ }^{\circ} \mathrm{C}$, the quantity of ACs cycles is desirable. However, under excessive high or low ambient temperature, the quantity of ACs cycle significantly increases, which exerts too much influence on consumers. Therefore, ambient temperature is a prominent issue when utilizing aggregated ACs load to provide frequency control ancillary service. Better results could only be obtained under proper ambient temperature. 

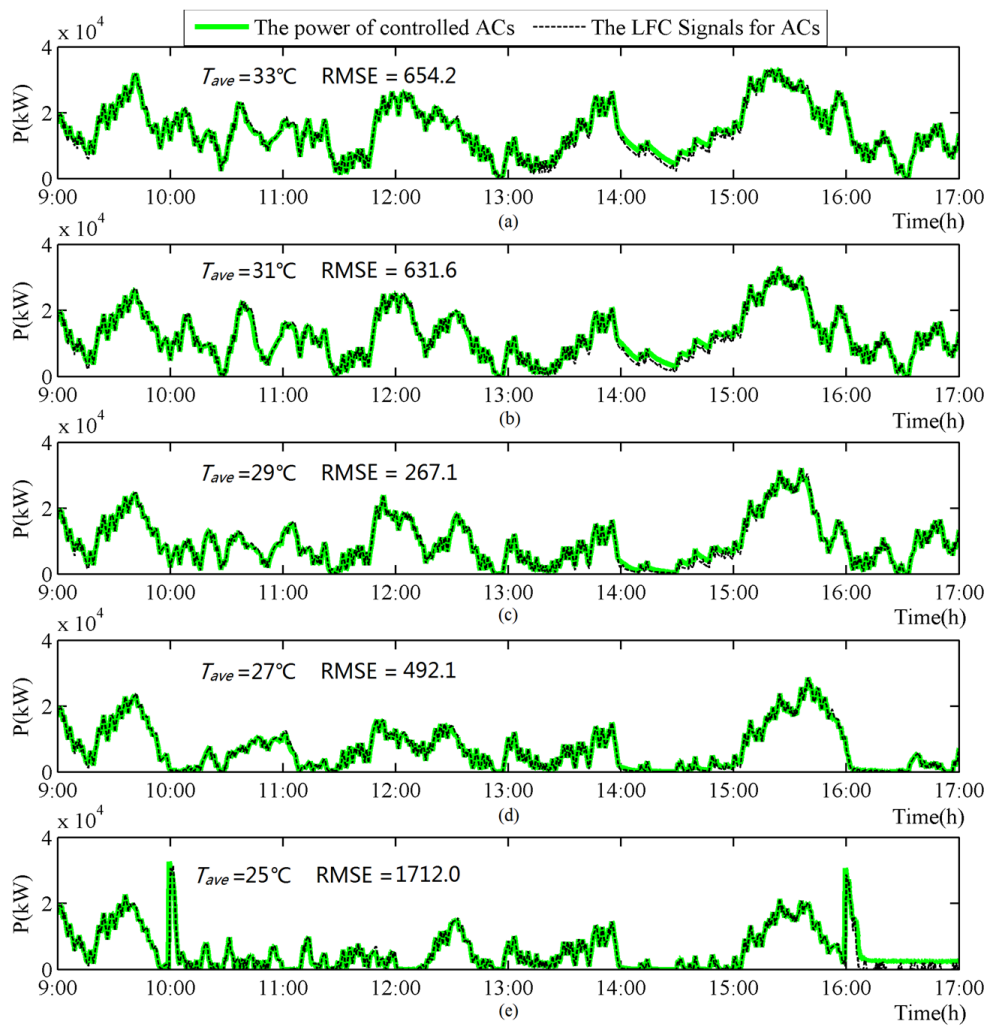

Figure 16. Impact of different ambient temperature on tracking LFC signals. (a) $\mathrm{T}_{\text {ave }}=33^{\circ} \mathrm{C}$; (b) $T_{\text {ave }}=31^{\circ} \mathrm{C} ;$ (c) $T_{\text {ave }}=29^{\circ} \mathrm{C} ;$ (d) $T_{\text {ave }}=27^{\circ} \mathrm{C} ;\left(\right.$ e) $T_{\text {ave }}=25^{\circ} \mathrm{C}$.
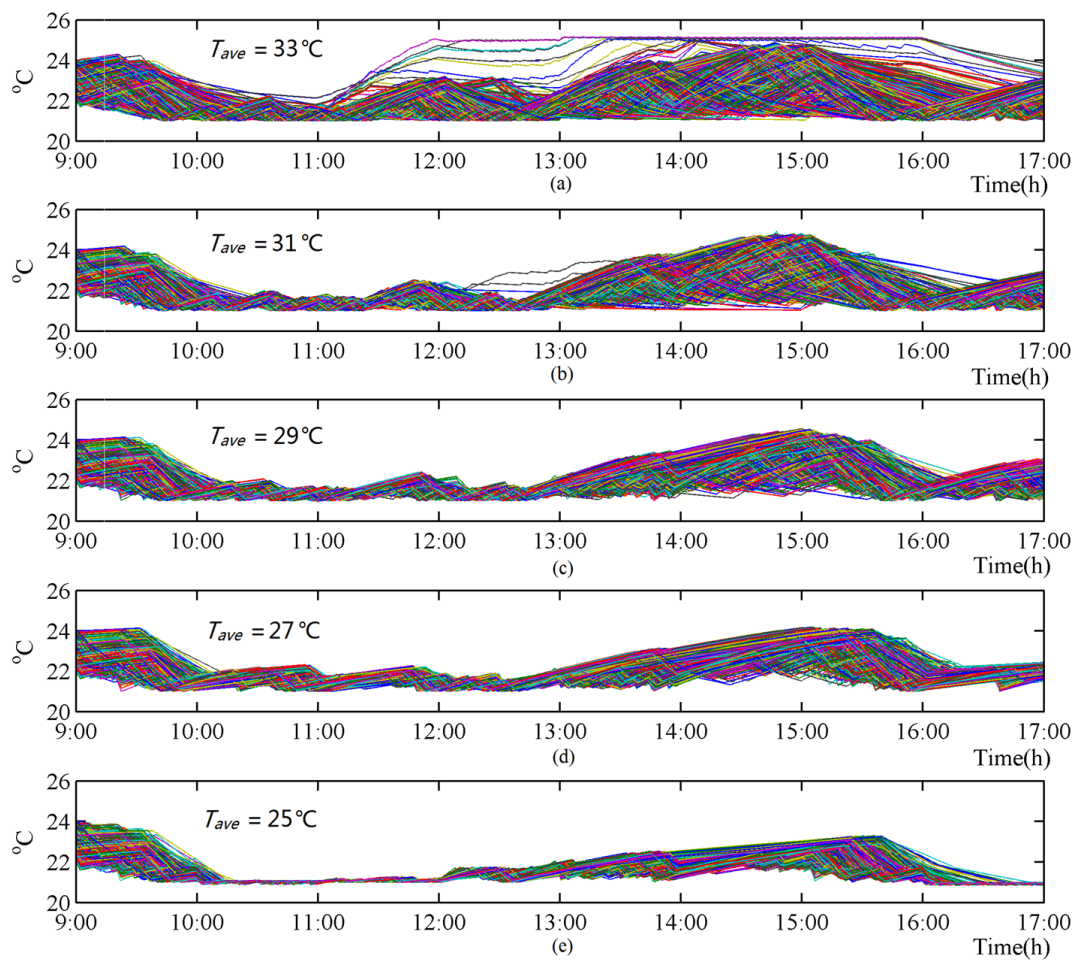

Figure 17. Impact of different ambient temperature on room temperature profiles. (a) $\mathrm{T}_{\mathrm{ave}}=33^{\circ} \mathrm{C}$; (b) $T_{\text {ave }}=31^{\circ} \mathrm{C} ;\left(\right.$ c) $T_{\text {ave }}=29^{\circ} \mathrm{C} ;\left(\right.$ d) $T_{\text {ave }}=27^{\circ} \mathrm{C} ;\left(\right.$ e) $T_{\text {ave }}=25^{\circ} \mathrm{C}$. 


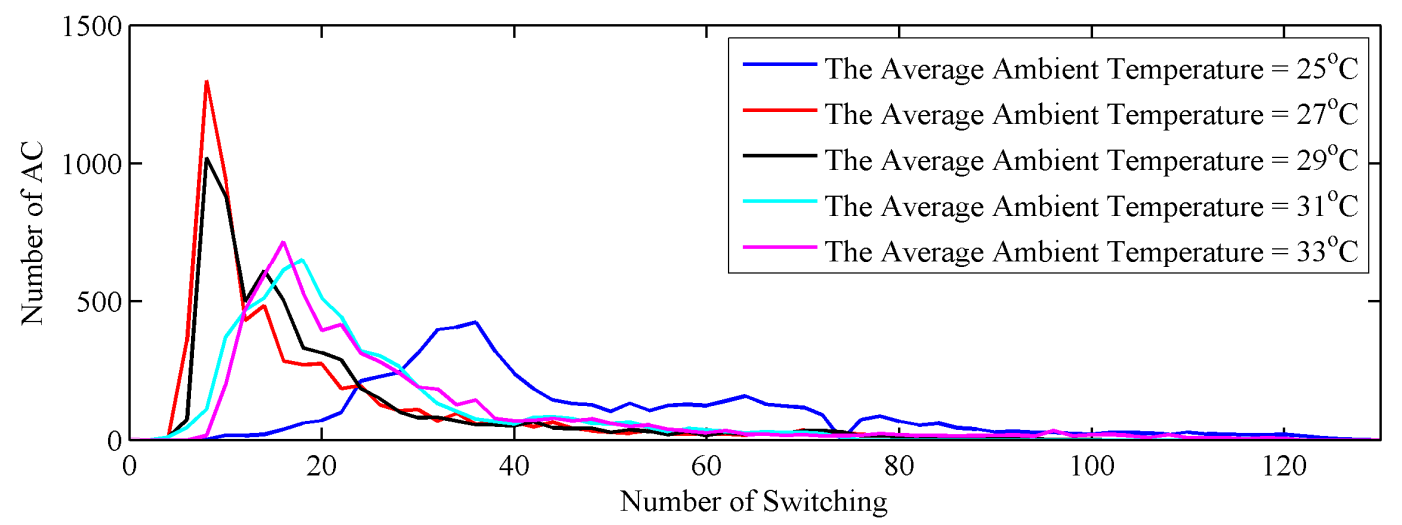

Figure 18. Impact of different ambient temperature on ACs cycles.

\subsection{Case E: Impacts of Deadband Changes on Results}

In this case, we compare the simulation results with three temperature deadband settings, with all the other parameters remaining the same as those used in Case A. It could be concluded from Figure 19 that the wider temperature deadband, the better LFC signal tracking quality, which results in high quality of frequency deviation as shown in Table 8.
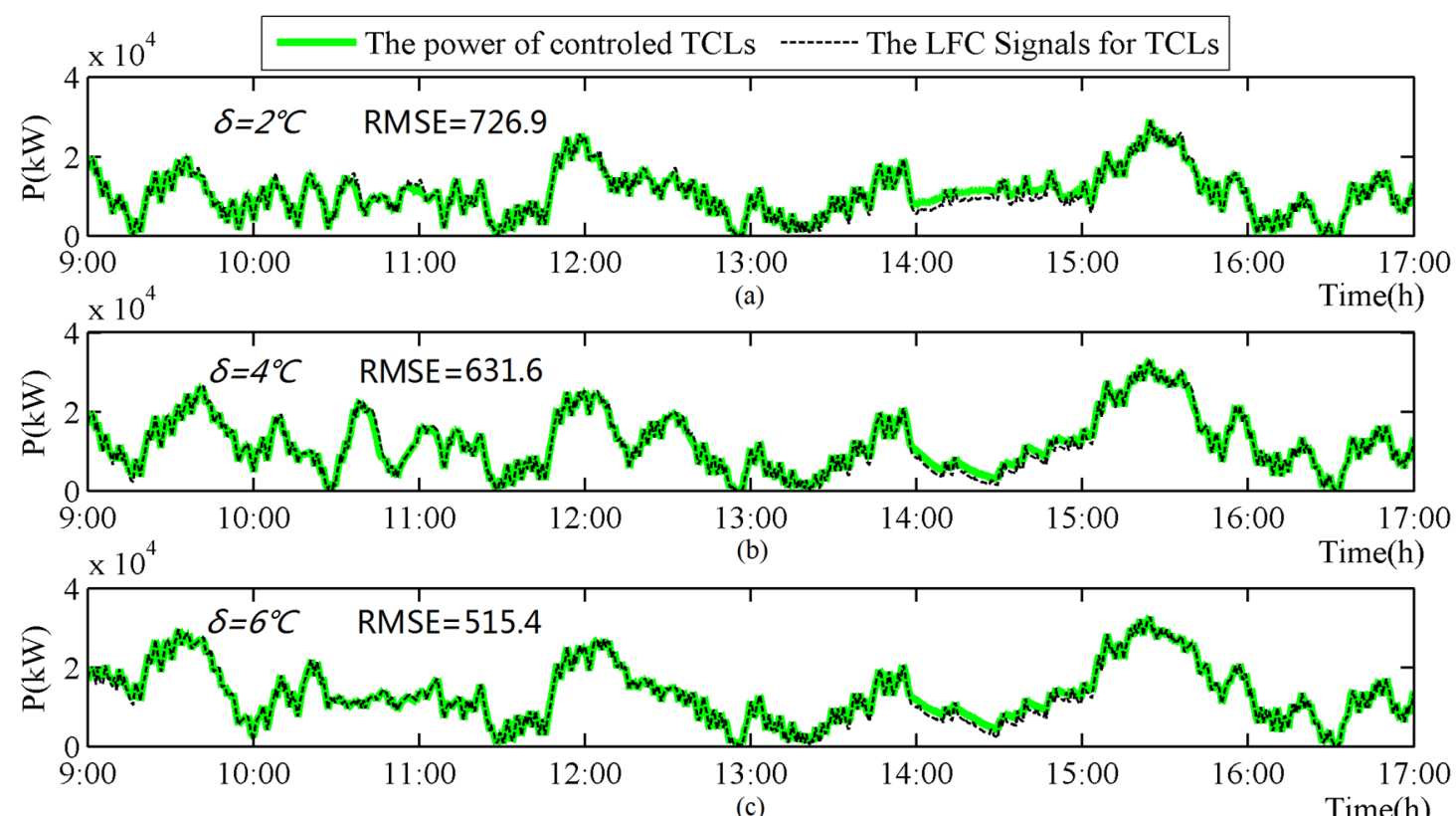

Figure 19. Impact of different temperature deadband on tracking LFC signals. (a) $\delta=2^{\circ} \mathrm{C}$; (b) $\delta=4^{\circ} \mathrm{C}$; (c) $\delta=6^{\circ} \mathrm{C}$.

Table 8. Impact of different temperature deadband on quality of frequency deviation.

\begin{tabular}{cccc}
\hline Temperature deadband & MAX (Hz) & MIN (Hz) & RMS (Hz) \\
\hline $2{ }^{\circ} \mathrm{C}$ & 0.1553 & -0.1660 & 0.365 \\
$4{ }^{\circ} \mathrm{C}$ & 0.1484 & -0.1633 & 0.362 \\
$6{ }^{\circ} \mathrm{C}$ & 0.1426 & -0.1605 & 0.359 \\
\hline
\end{tabular}

When the deadband is narrower, the capability of ACs load to follow the LFC signal is reduced because tracking the signals will partially synchronize diversified AC loads (Figure 20). 

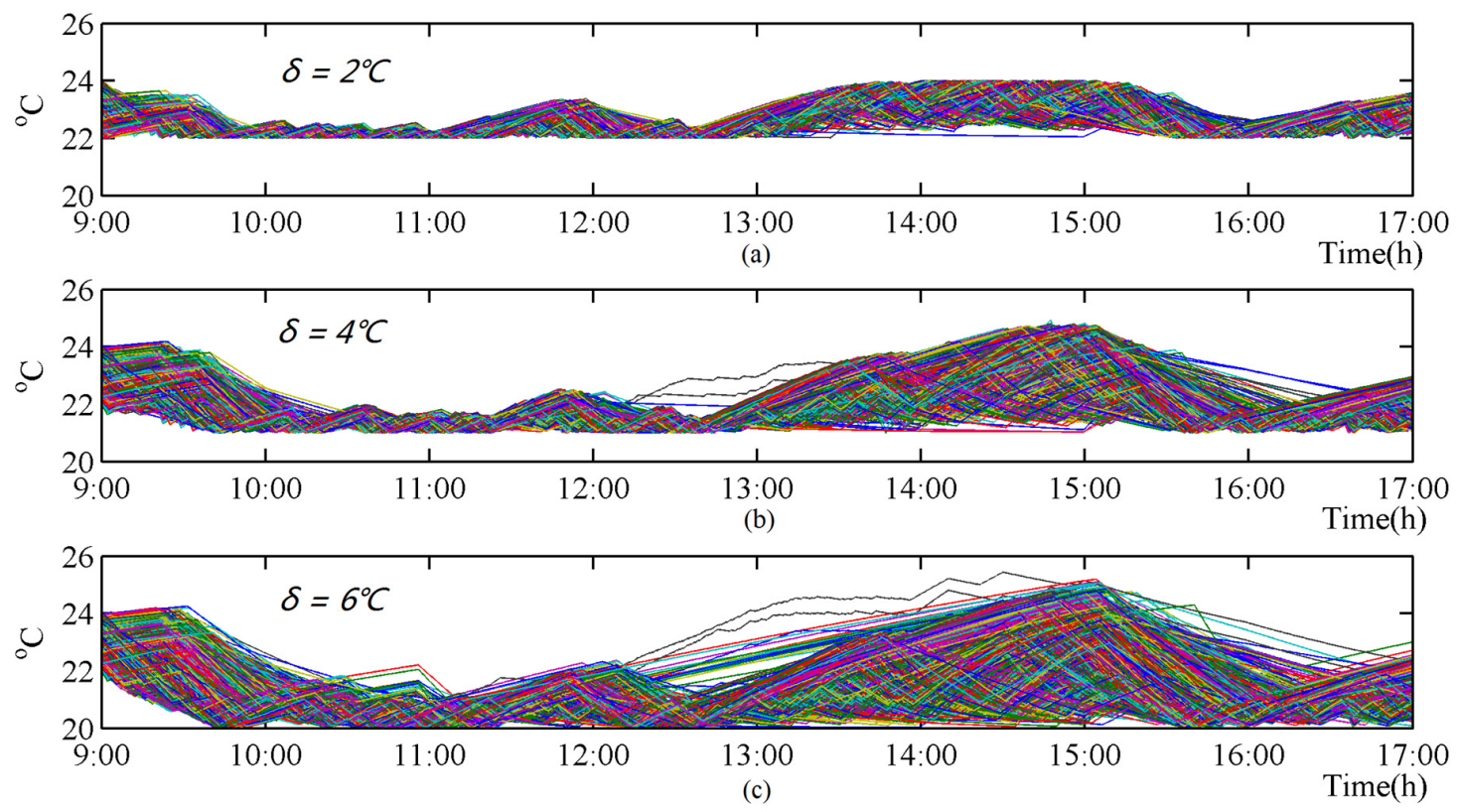

Figure 20. Impact of different temperature deadband on room temperature profiles. (a) $\delta=2{ }^{\circ} \mathrm{C}$; (b) $\delta=4{ }^{\circ} \mathrm{C} ;\left(\right.$ c) $\delta=6{ }^{\circ} \mathrm{C}$.

Figure 21 illustrates the impact of different temperature deadband on AC cycles. It could be seen that when deadband decreases from $6{ }^{\circ} \mathrm{C}$ to $2{ }^{\circ} \mathrm{C}$, the quantity of ACs cycles significantly increases, which will shorten the life of ACs. Therefore, wider setting of deadband could not only obtain smaller frequency fluctuations but also reduce impacts on AC service life.

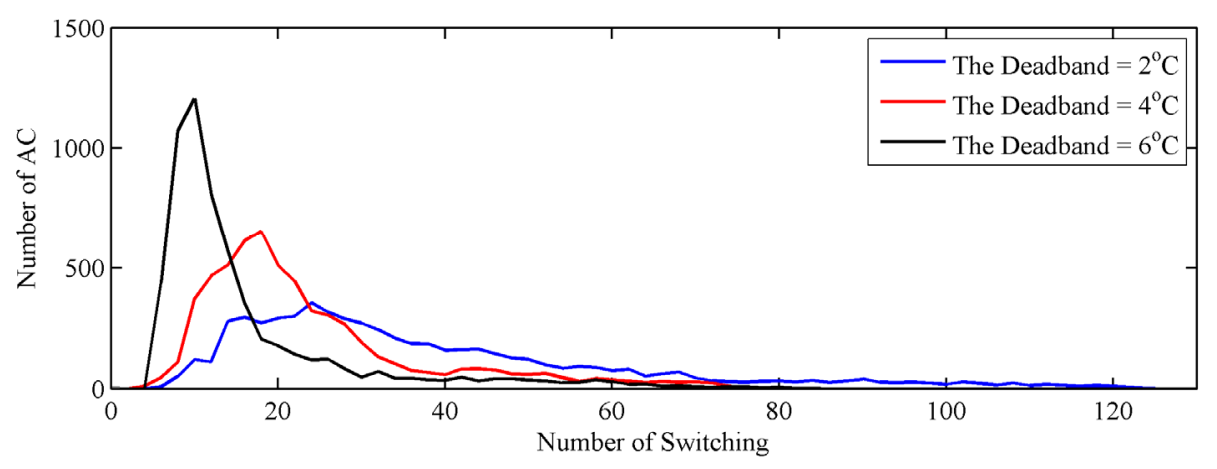

Figure 21. Impact of different temperature deadband on ACs cycles.

\section{Conclusions}

In this paper, we focus on the integration of aggregated ACs into power systems. A change-time-priority-list method is used to dispatch a collection of ACs for Supplementary Load Frequency Control to reduce the frequency fluctuations caused by wind power integration. A control framework of combining the Supplementary LFC with the traditional LFC is presented in this paper. The effectiveness of the proposed method has been confirmed by simulations on a single-area power system with wind power integration. The impact of ambient temperature changes and customer room temperature preferences is also considered. The simulation result demonstrates that the Supplementary LFC provided by ACs could closely track the LFC signals and reduce the frequency deviation effectively as well as maintain customers' comfort and load diversity. This paper does not discuss the communication cost of the proposed control framework and AC model. Since several temperatures are needed for the model, the communication cost of transmitting a large amount of 
temperature data can not be ignored, and we will consider it in our future work. Other future work will focus on more efficient methods for controlling ACs, the incentive mechanism for AC-owners and its applications in the pilot project.

Acknowledgments: This research was supported by the National Natural Science Foundation of China (71471036, 51277028) and the National High Technology Research and Development of China 863 Program (2015AA050401).

Author Contributions: Lei Zhou designed the model and performed the simulations. Lei Zhou, Yang Li and Beibei Wang analyzed the data. Zhe Wang and Xiaoqing Hu have proposed the research topic and provided materials and analysis tools. All authors contributed to the writing of the manuscript, and have read and approved the final manuscript.

Conflicts of Interest: The authors declare no conflict of interest.

\section{References}

1. U.S. Department of Energy. 20\% Wind Energy by 2030. Available online: http://www1.eere.energy.gov/ windandhydro/wind_2030.html (accessed on 2 September 2009).

2. China Power. The New Installed Wind Capacity of China in 2014. Available online: http:/ /www.chinapower.com.cn/article/1281/art1281185.asp (accessed on 5 February 2015).

3. Mukherjee, S.; Teleke, S.; Bandaru, V. Frequency Response and Dynamic Power Balancing in Wind and Solar Generation. In Proceedings of the 2011 IEEE Power Engineering Society General Meeting, San Diego, CA, USA, 24-29 July 2011.

4. Bevran, H.; Ghosh, A.; Ledwich, G. Renewable energy sources and frequency regulation: Survey and new perspectives. IET Renew. Power Gen. 2010, 4, 438-457. [CrossRef]

5. Saadat, H. Power System Analysis, 2nd ed.; BS Publications: Hyderabad, India, 2007; pp. 1-5.

6. Kundur, P. Power System Stability and Control, 1st ed.; McGraw-Hill: New York, NY, USA, 1994; pp. 3-16.

7. Faria, P.; Vale, Z.; Baptista, J. Demand Response Programs Design and Use Considering Intensive Penetration of Distributed Generation. Energies 2015, 8, 6230-6246. [CrossRef]

8. Callaway, D.; Hiskens, I. Achieving controllability of electric loads. Proc. IEEE 2011, 99, 184-199. [CrossRef]

9. Callaway, D. Tapping the energy storage potential in electric loads to deliver load following and regulation, with application to wind energy. Energy Convers. Manag. 2009, 50, 1389-1400. [CrossRef]

10. Lu, N.; Katipamula, S. Control strategies of thermostatically controlled appliances in a competitive electricity market. In Proceedings of the IEEE Power Engineering Society General Meeting, San Francisco, CA, USA, 12-16 June 2005.

11. Li, M.; Mu, H.; Li, H. Analysis and Assessments of Combined Cooling, Heating and Power Systems in Various Operation Modes for a Building in China, Dalian. Energies 2013, 6, 2446-2467. [CrossRef]

12. Valancius, R.; Jurelionis, A.; Dorosevas, V. Method for Cost-Benefit Analysis of Improved Indoor Climate Conditions and Reduced Energy Consumption in Office Buildings. Energies 2013, 6, 4591-4606. [CrossRef]

13. Katipamula, S.; Lu, N. Evaluation of residential HVAC control strategies for demand response programs. ASHRAE Trans. 2006, 112, 535-546.

14. Schweppe, F.; Tabors, R.; Kirtley, J.; Outhred, H.; Pickel, F.; Cox, A. Homeostatic utility control. IEEE Trans. Power App. Syst. 1980, 99, 1151-1163. [CrossRef]

15. Ihara, S.; Schweppe, F.C. Physically based modeling of cold load pickup. IEEE Trans. Power App. Syst. 1981, 9, 4142-4150. [CrossRef]

16. Malhame, R.; Chong, C.Y. Electric load model synthesis by diffusion approximation of a high-order hybrid-state stochastic system. IEEE Trans. Autom. Control 1981, 30, 854-860. [CrossRef]

17. Parkinson, S.; Wang, D.; Crawford, C.; Djilali, N. Comfort-constrained distributed heat pump management. In Proceedings of the International Conference on Smart Grid and Clean Energy Technologies, Chengdu, China, 27-30 September 2011.

18. Parkinson, S.; Wang, D.; Crawford, C.; Djilali, N. Wind integration in self-regulating electric load distributions. Energy Syst. 2012, 3, 341-377. [CrossRef]

19. Borhan, M.S.; Hao, H.; Kameshwar, P. Fast Regulation Service Provision via Aggregation of Thermostatically Controlled Loads. In Proceedings of the 47th Annual Hawaii International Conference on System Sciences, Waikoloa, HI, USA, 6-9 January 2014. 
20. Mathieu, J.L.; Koch, S.; Callaway, D.S. State Estimation and Control of Electric Loads to Manage Real-Time Energy Imbalance. IEEE Trans. Power Syst. 2013, 28, 430-440. [CrossRef]

21. Bashash, S.; Fathy, H.K. Modeling and control insights into demand-side energy management through setpoint control of thermostatic loads. In Proceedings of the American Control Conference, San Francisco, CA, USA, 29 June-1 July 2011.

22. Zhang, W.; Kalsi, K.; Fuller, J.; Elizondo, M.; Chassin, D. Aggregate model for heterogeneous thermostatically controlled loads with demand response. In Proceedings of the 2012 IEEE Power and Energy Society General Meeting, San Diego, CA, USA, 22-26 July 2012.

23. Pahwa, A.; Brice, C.W. Modeling and system-identification of residential air conditioning load. IEEE Trans. Power App. Syst. 1985, 104, 1418-1425. [CrossRef]

24. El-Ferik, S.; Malhamé, R. Identification of alternating renewal electric load models from energy measurements. IEEE Trans. Autom. Control 1994, 39, 1184-1196. [CrossRef]

25. El-Ferik, S.; Hussain, S.; Al-Sunni, F. Identification of physically based models of residential air-conditioners for direct load control management. In Proceedings of the 5th Asian control conference, Melbourne, Australia, 20-23 July 2004.

26. Ning, L.; Chassin, D.P. A state-queueing model of thermostatically controlled appliances. IEEE Trans. Power Syst. 2004, 19, 1666-1673.

27. Ning, L. An evaluation of the HVAC load potential for providing load balancing service. IEEE Trans. Smart Grid 2012, 3, 1263-1270.

28. Ning, L.; Yu, Z. Design considerations of a centralized load controller using thermostatically controlled appliances for continuous regulation reserves. IEEE Trans. Smart Grid 2013, 4, 914-921.

29. Wang, D.; Ge, S.; Jia, H.; Wang, C.; Zhou, Y.; Lu, N.; Kong, X. A Demand Response and Battery Storage Coordination Algorithm for Providing Microgrid Tie-Line Smoothing Services. IEEE Trans. Sustain. Energy 2014, 5, 476-486. [CrossRef]

30. Yu, Z.; Ning, L. Parameter selection for a centralized thermostatically controlled appliances load controller used for intra-hour load balancing. IEEE Trans. Smart Grid 2013, 4, 2100-2108.

31. Jiang, J.; Zhang, X. Electric Control System of Inverter Air-conditioning Based on Fuzzy Control. In Proceedings of the 2010 2nd International Conference on Information Science and Engineering, Hangzhou, China, 4-6 December 2010.

32. Zhao, J.; Lian, X.; Wu, Y.; Zhang, X.; Wang, S. Design of Wireless Temperature and Humidity Data Collection System Based on MSP430 and CC2530. In Proceedings of the 2012 3rd International Conference on System Science, Engineering Design and Manufacturing Informatization, Chengdu, China, 20-21 October 2012.

33. Perfumo, C.; Kofman, E.; Braslavsky, J.H.; Ward, J.K. Load management: Model-based control of aggregate power for populations of thermostatically controlled loads. Energy Convers. Manag. 2012, 55, 36-48. [CrossRef]

(C) 2015 by the authors; licensee MDPI, Basel, Switzerland. This article is an open access article distributed under the terms and conditions of the Creative Commons by Attribution (CC-BY) license (http:/ / creativecommons.org/licenses/by/4.0/). 